\title{
Neurobeachin regulates neurotransmitter receptor trafficking to synapses
}

\author{
Ramya Nair, ${ }^{1}$ Juliane Lauks, ${ }^{2,3}$ SangYong Jung, ${ }^{1}$ Nancy E. Cooke, ${ }^{4}$ Heidi de Wit, ${ }^{2}$ Nils Brose, ${ }^{1}$ Manfred W. Kilimann, ${ }^{5}$ \\ Matthijs Verhage, ${ }^{2,3}$ and JeongSeop Rhee ${ }^{1}$ \\ 'Department of Molecular Neurobiology, Max Planck Institute of Experimental Medicine, 37075 Göttingen, Germany \\ 2Department of Functional Genomics and ${ }^{3}$ Department of Clinical Genetics, Center for Neurogenomics and Cognitive Research, Neuroscience Campus Amsterdam, \\ Vrije Universiteit and Vrije Universiteit Medical Center, 1081 HV Amsterdam, Netherlands \\ ${ }^{4}$ Department of Genetics and Medicine, Perelman School of Medicine, University of Pennsylvania, Philadelphia, PA 19104 \\ ${ }^{5}$ Department of Neuroscience, Uppsala University, 75124 Uppsala, Sweden
}

$\mathrm{T}$ he surface density of neurotransmitter receptors at synapses is a key determinant of synaptic efficacy. Synaptic receptor accumulation is regulated by the transport, postsynaptic anchoring, and turnover of receptors, involving multiple trafficking, sorting, motor, and scaffold proteins. We found that neurons lacking the $\mathrm{BEACH}$ (beige-Chediak/Higashi) domain protein Neurobeachin (Nbea) had strongly reduced synaptic responses caused by a reduction in surface levels of glutamate and $G A B A_{A}$ receptors. In the absence of Nbea, immature AMPA receptors accumulated early in the biosynthetic pathway, and mature $\mathrm{N}$-methyl-D-aspartate, kainate, and $\mathrm{GABA}_{\mathrm{A}}$ receptors did not reach the synapse, whereas maturation and surface expression of other membrane proteins, synapse formation, and presynaptic function were unaffected. These data show that Nbea regulates synaptic transmission under basal conditions by targeting neurotransmitter receptors to synapses.

\section{Introduction}

Strength and plasticity of neuronal synapses are controlled by modifications of the number and functionality of neurotransmitter receptors in the postsynaptic density. The number of functional synaptic receptors is regulated by a complex interplay between mobilization and immobilization, by internalization and local recycling, and by desensitization. Although many features of the activity-dependent local receptor trafficking mechanisms have been characterized, mechanisms that orchestrate the synaptic delivery of new receptors-from their biosynthesis and heteromeric assembly in the ER via their maturation in the Golgi apparatus to their final insertion into the target membrane-are poorly understood. These mechanisms have shared and unique features for different receptor types. In the ER, the assembly of oligomeric glutamate and $\mathrm{GABA}_{\mathrm{A}}$ receptors and the combination of receptor subunits are controlled by different

R. Nair and J. Lauks contributed equally to this paper.

Correspondence to Matthijs Verhage: matthijs.verhage@cncr.vu.nl; or Jeong Seop Rhee: rhee@em.mpg.de

Abbreviations used in this paper: DIV, day in vitro; EPSC, excitatory PSC; ERGIC, ER-Golgi intermediate compartment; GABA, $\gamma$-aminobutyric acid; IPSC, inhibitory PSC; KO, knockout; mEPSC, miniature EPSC; mIPSC, miniature IPSC; mPSC, miniature PSC; Nbea, Neurobeachin; NMDA, N-methyl-D-aspartate; NPY, neuropeptide Y; PSC, postsynaptic current; RRP, readily releasable pool; SV, synaptic vesicle; TTX, tetrodotoxin; VIAAT, vesicular inhibitory amino acid transporter; WT, wild type. scaffolding, adapter, and trafficking proteins (Prybylowski and Wenthold, 2004; Greger and Esteban, 2007; Jacob et al., 2008). Likewise, the molecular determinants of motor-based intracellular transport of different receptor types are different (Hirokawa and Takemura, 2004).

Here, we identified the putative trafficking protein Neurobeachin (Nbea) as a regulator of the specific targeting of several major ionotropic excitatory and inhibitory receptors in neurons. The multidomain protein Nbea $(327 \mathrm{kD})$ is selectively expressed in neurons and endocrine cells (Wang et al., 2000). Its C terminus contains a conserved BEACH (beige-Chediak/Higashi) domain, a pleckstrin homology domain, and WD40 repeats (Wang et al., 2000, 2002; Gebauer et al., 2004), an arrangement that is shared within a family of eight BEACH domain proteins. Mutations in the BEACH domain of LYST cause Chediak-Higashi syndrome in humans and beige syndrome in mice, characterized by enlarged lysosomes and related organelles (Burkhardt et al., 1993; Zhao et al., 1994; Nagle et al., 1996; Introne et al., 1999). Mutations in the BEACH protein NBEAL2 cause Gray platelet syndrome with perturbations in the biogenesis of secretory $\alpha$ granules

(c) 2013 Nair et al. This article is distributed under the terms of an AttributionNoncommercial-Share Alike-No Mirror Sites license for the first six months after the publication date (see http://www.rupress.org/terms). After six months it is available under a Creative Commons License (Attribution-Noncommercial-Share Alike 3.0 Unported license, as described at http://creativecommons.org/licenses/by-nc-sa/3.0/). 
and other endomembrane compartments (Albers et al., 2011; Gunay-Aygun et al., 2011; Kahr et al., 2011). Human mutations in LRBA cause a syndrome of immunological abnormalities (Lopez-Herrera et al., 2012). Heterozygous rearrangements in the human NBEA gene were detected in patients with autism (Castermans et al., 2003) or with multiple myeloma (O'Neal et al., 2009), and reduced Nbea expression causes overweight patients (Olszewski et al., 2012).

In neurons, Nbea is recruited to tubulovesicular endomembranes in a GTP $\gamma$ S-stimulated manner (Wang et al., 2000), which led to the notion that Nbea might regulate post-Golgi protein trafficking, and Nbea associates with the trafficking protein vacuolar protein sorting 35 in a complex with glycine receptor $\beta$ subunits (del Pino et al., 2011). Defects in synapse morphology, enrichment of synaptic molecules, and synaptic transmission were described in two Nbea knockout (KO) mouse lines (Su et al., 2004; Medrihan et al., 2009; Niesmann et al., 2011). We now demonstrate that defects in the synaptic localization of ionotropic receptors for the key excitatory and inhibitory neurotransmitters are a major cause of these defects and that, in the absence of Nbea, these receptors accumulate in the biosynthetic pathway. Our data identify Nbea as a general organizer of synaptic receptor targeting with a major role in the regulation of synaptic transmission.

\section{Results}

Defective glutamatergic and GABAergic synaptic transmission in $\mathbf{N b e a ~} \mathbf{K O}$ neurons As Nbea KO mice die perinatally (Su et al., 2004; Medrihan et al., 2009), we used autaptic and high-density cultures of hippocampal and striatal neurons from E18 embryos to study the functional consequences of Nbea KO. We detected no significant morphological or functional differences between wild-type (WT) and heterozygous Nbea KO neurons (Fig. S1 and Tables S1 and S4) and pooled all data obtained with these genotypes, designating them as control.

Evoked excitatory postsynaptic current (PSC; EPSC) amplitudes in Nbea KO hippocampal neurons and inhibitory PSC (IPSC) amplitudes in Nbea KO striatal neurons were reduced by 64 and $67 \%$, respectively, as compared with control cells (Fig. 1, A-C; and Table S1). Similar changes were observed in postsynaptic responses triggered by hypertonic sucrose solution, which causes the release of the readily releasable pool (RRP) of synaptic vesicles (SVs; Rosenmund and Stevens, 1996; Jockusch et al., 2007). We found that glutamatergic and GABAergic Nbea KO neurons showed reductions in apparent RRP sizes of 75 and $70 \%$, respectively (Fig. 1, A, B, and D; and Table S1). The vesicular release probabilities $\left(\mathrm{P}_{\mathrm{vr}}\right)$ in the two types of neurons, calculated by dividing the charge transferred during action potential evoked PSCs by the RRP charge, were slightly reduced upon Nbea KO (Fig. 1 E and Table S1). Amplitudes of miniature EPSCs (mEPSCs) and miniature IPSCs (mIPSCs) were reduced by 23 and 16\%, respectively. The corresponding $\mathrm{mEPSC} / \mathrm{mIPSC}$ frequencies were reduced by $\sim 60 \%$ (Fig. 1, F-I; and Table S1), like evoked EPSC/IPSC amplitudes and the corresponding responses to hypertonic sucrose solution
(Fig. 1, C and D). In analyses of short-term plasticity, EPSC and IPSC amplitudes in hippocampal and striatal Nbea KO neurons depressed progressively during 10- and 40-Hz stimulation trains to the same steady-state depression levels as control cells (Fig. 1, J and K).

We next examined the effects of voltage-gated $\mathrm{Ca}^{2+}$ channel-independent activation of the presynaptic release machinery by the $\mathrm{Ca}^{2+}$ ionophore calcimycin (Jockusch et al., 2007). Irrespective of the genotype and transmitter type, elevation of intracellular $\mathrm{Ca}^{2+}$ levels $\left[\mathrm{Ca}^{2+}\right]_{\mathrm{i}}$ by $10 \mu \mathrm{M}$ calcimycin triggered massive release of $\mathrm{SVs}$ and complete depletion of all releasable SVs. Calcimycin responses in Nbea KO cells were reduced to a similar degree as responses to hypertonic sucrose solution (Fig. 2, A and B; and Table S1), indicating that synaptic transmission is severely affected in Nbea $\mathrm{KO}$ neurons and that the dominant defect is downstream of presynaptic $\mathrm{Ca}^{2+}$ influx. In addition, we determined the total number of presynaptically active synapses in glutamatergic Nbea KO neurons by combining antibody staining with fixable FM1-43, which stains synapses with exocytosis and endocytosis activity. The proportion of active synapses was similar in Nbea KO and control cells (Fig. 2, $\mathrm{C}$ and D; and Table S4), and the total number of synapses in Nbea $\mathrm{KO}$ neurons was not altered (see Fig. 7, C and D), indicating that the synaptic transmission deficits in Nbea KO neurons are not caused by changes in the number of active synapses or to a profound presynaptic defect.

To further test whether presynaptic defects contribute to the reduction of synaptic strength in Nbea $\mathrm{KO}$ neurons, we established microisland cultures of cell pairs on a single astrocyte microisland, consisting of one hippocampal glutamatergic and one striatal GABAergic neuron (Fig. 2 E and Table S2). The combination of an inhibitory and an excitatory neuron on a single island allowed us to discriminate autaptic and intercellular synaptic glutamate-evoked responses, and seeding together inhibitory and excitatory neurons from Nbea $\mathrm{KO}$ and control genotypes allowed us to determine presynaptic and postsynaptic contributions to the Nbea KO phenotype. The EPSC amplitudes from pairs consisting of two KO neurons were smaller than those of two control neurons. In contrast, the PSCs recorded in control neurons receiving synaptic inputs from an Nbea KO neuron were normal (Fig. $2 \mathrm{E}$ and Table S2). Together with the facts that FM1-43 dye loading is unaltered in KO cells (Fig. 2, $\mathrm{C}$ and $\mathrm{D})$, responses evoked by action potentials, hypertonic sucrose solution, and calcimycin are similarly reduced in $\mathrm{KO}$ neurons (Fig. 2, A and B), and presynaptic plasticity is unaffected (Fig. 1, J and K). The paired recordings indicate that the altered synaptic strength of Nbea KO neurons cannot be explained by presynaptic defects.

Less functional neurotransmitter receptors at Nbea KO synapses

To further study the causes of the reduced synaptic transmission in Nbea $\mathrm{KO}$ neurons, we measured their responses to exogenous application of glutamate and $\mathrm{GABA}_{\mathrm{A}}$ receptor agonists (Jones and Westbrook, 1996). Compared with control cells from days in vitro (DIV) 11-15, Nbea KO neurons exhibited dramatic reductions in their responses to $10 \mu \mathrm{M}$ kainate, $30 \mu \mathrm{M}$ glutamate, 
A

Glutamatergic neurons

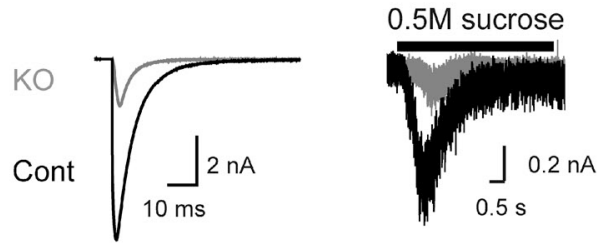

B

GABAergic neurons
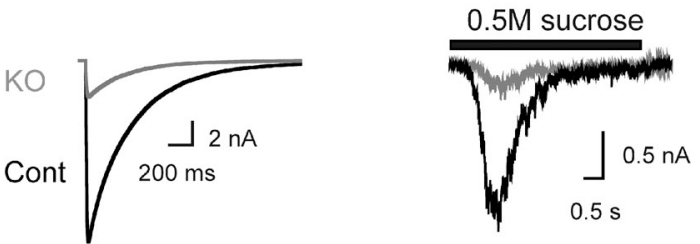

\section{Hippocampus Striatum}

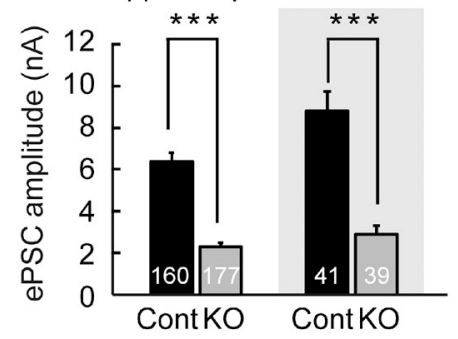

F

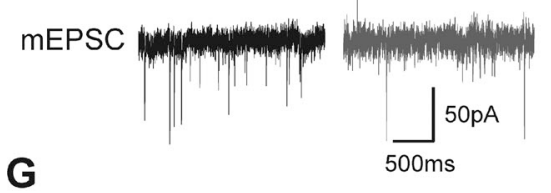

mIPSC<smiles>C=C(C)CCCC</smiles><smiles>CCCCCCCCCCCCC</smiles>

J Hippocampus
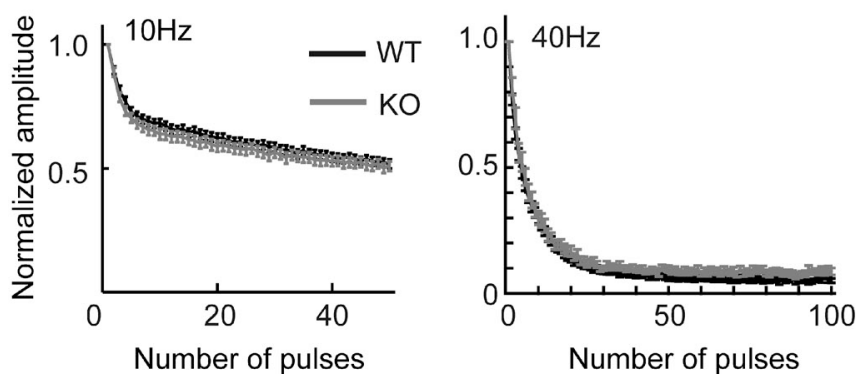

Number of pulses
D Hippocampus Striatum

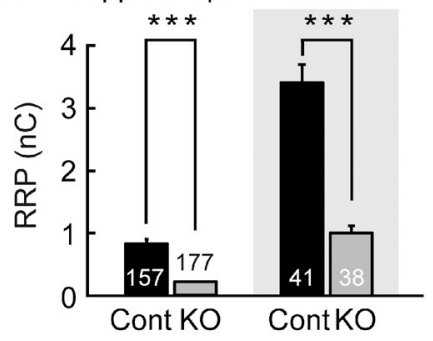

H

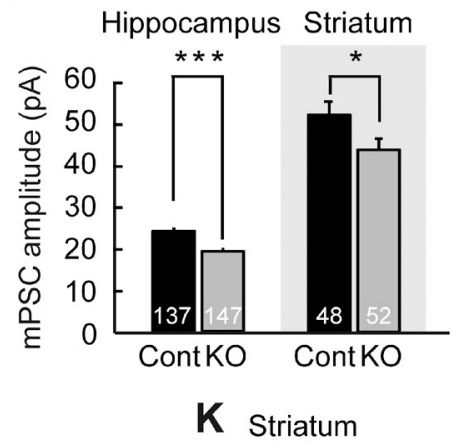

E Hippocampus Striatum

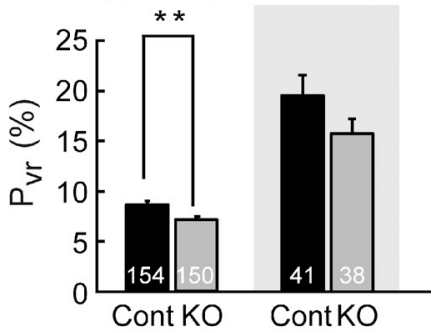

I

Hippocampus Striatum

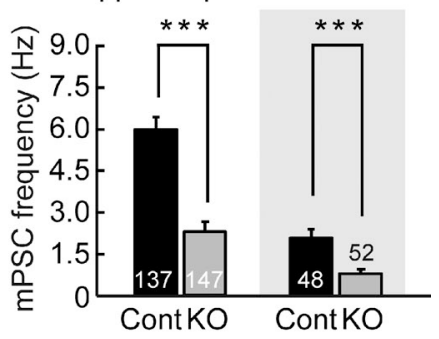

Figure 1. Reduced evoked and spontaneous synaptic transmission in Nbea KO neurons. (A) Traces of depolarization-evoked EPSCs (left) and responses after application of hypertonic sucrose solution (right) in glutamatergic Nbea KO (gray) and control (Cont) neurons (black). (B) Traces as in A but for depolarization-evoked IPSCs and responses after application of hypertonic sucrose solution in GABAergic neurons. (C) Mean evoked EPSC amplitudes in hippocampal glutamatergic (left) and striatal GABAergic cells (right, on gray background) of control and Nbea KO mice. (D) Mean charge transfer during the response to hypertonic sucrose solution (apparent RRP size estimate) in hippocampal glutamatergic (left) and striatal GABAergic cells (right, on gray background) of control and Nbea KO mice. (E) Average vesicular release probability $P_{\mathrm{vr}}$ in hippocampal glutamatergic (left) and striatal GABAergic cells (right, on gray background) of control and Nbea KO mice. The $P_{\mathrm{vr}}$ is expressed as the percentage of the RRP and was calculated by dividing the charge transfer during an action potential evoked response by the charge transfer measured during a response to hypertonic sucrose solution (reflecting the apparent RRP). (F) mEPSC traces recorded at -70-mV holding potential in the presence of $300 \mathrm{nM}$ TTX in glutamatergic Nbea KO and control neurons. (G) mIPSC traces recorded at $-70-\mathrm{mV}$ holding potential in the presence of $300 \mathrm{nM}$ TTX in GABAergic Nbea KO (gray) and control neurons (black). (H) Mean mPSC amplitudes in hippocampal glutamatergic (left) and striatal GABAergic cells (right, on gray background) of control and Nbea KO mice. (I) Mean mPSC frequencies in hippocampal glutamatergic (left) and striatal GABAergic cells (right, on gray background) of control and Nbea KO mice. (J) Evoked EPSC depression during 10-Hz (left; control, $n=94$; Nbea KO, $n=69$ ) and $40-\mathrm{Hz}$ (right; control, $n=35 ; \mathrm{Nbea} \mathrm{KO}, n=32$ ) stimulation trains. Data were normalized to the first response in the train. (K) Evoked IPSC depression during 10-Hz (left; control, $n=94 ; \mathrm{Nbea} \mathrm{KO,} n=69$ ) and 40-Hz (right; control, $n=35$; Nbea KO, $n=32$ ) stimulation trains. Data were normalized to the first response in the train. Error bars indicate SEM. The numbers of cells analyzed are given in/above the histogram bars $\left({ }^{*}, \mathrm{P}<0.05 ; * *, \mathrm{P}<0.01 ; * * *, \mathrm{P}<0.001\right.$ in Student's $t$ test). 
A Hippocampus

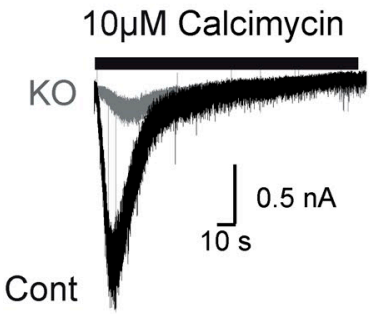

Striatum

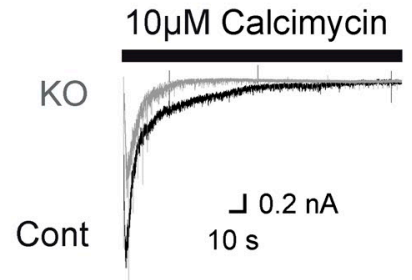

B

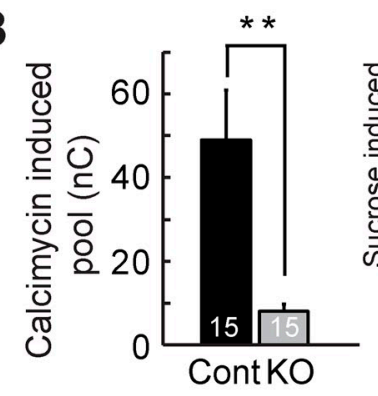

C
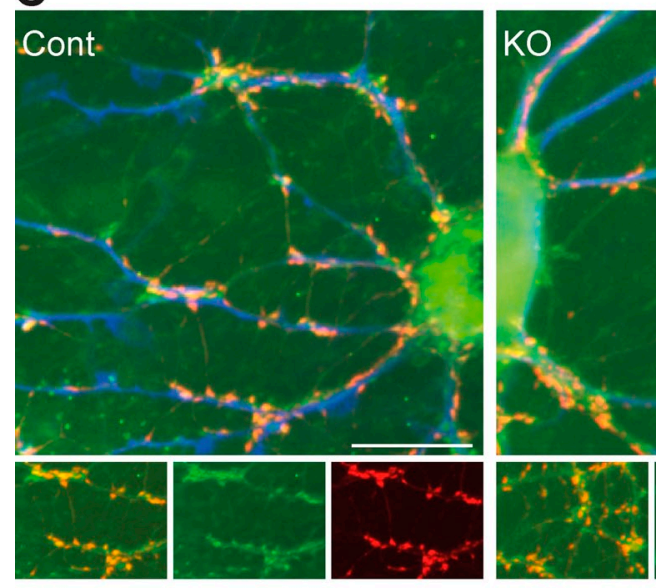

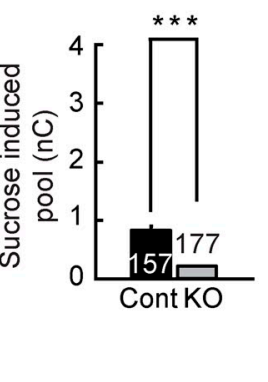

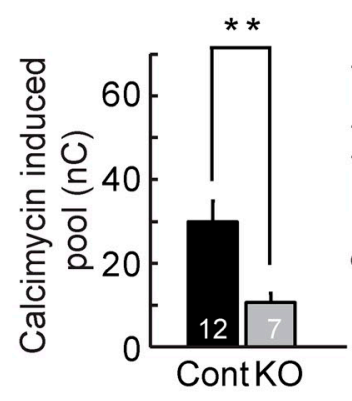

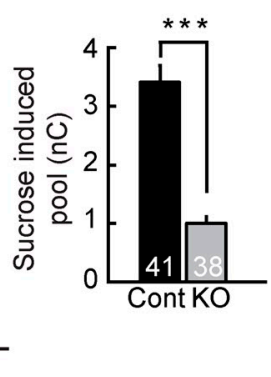

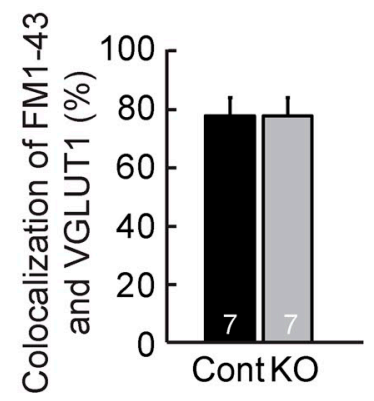
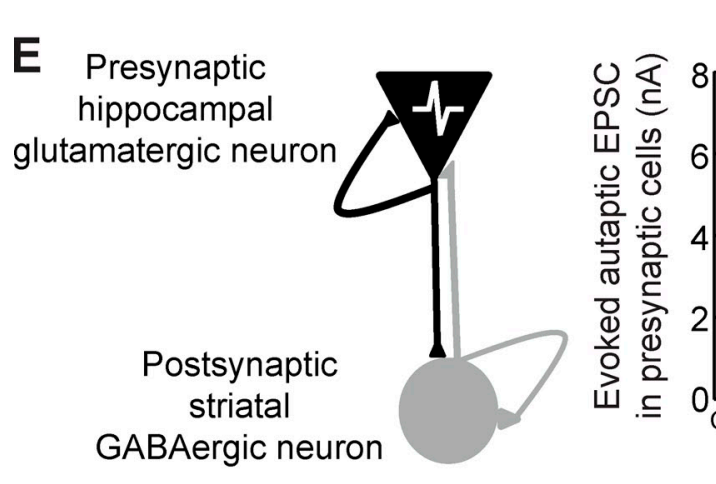

Hippocampus

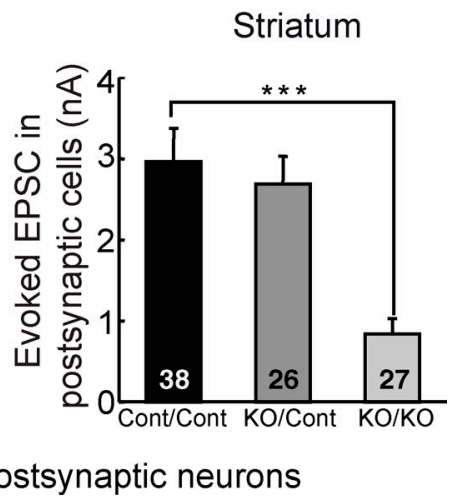

Figure 2. Unaltered presynaptic function in Nbea KO neurons. (A, left) Traces of calcimycin triggered (10 $\mu M)$ EPSCs in glutamatergic Nbea KO and control (Cont) neurons. (right) Traces of calcimycin triggered (10 $\mu$ M) IPSCs in GABAergic Nbea KO and control neurons. (B) Mean charge transfer during calcimycin triggered PSCs in hippocampal glutamatergic (left) and striatal GABAergic cells (right) of control and Nbea KO mice. The smaller histograms show corresponding data obtained with stimulation by hypertonic sucrose solution (see Fig. 1, A, B, and D). (C) Control and Nbea KO neurons loaded with FM1-43 (green) and costained for VGLUT1 (red) and MAP2 (blue). Bars: (main images) 10 \%m; (enlarged images) 5 mm. (D) Quantification of VGLUT1/ FM1-43 colocalization in control and Nbea KO neurons. (E) Recordings from pairs of neurons of different transmitter type on microislands as indicated in the diagram on the left. In each of the three genotype configurations tested (i.e., presynaptic glutamatergic cell control or Nbea KO and postsynaptic GABAergic cell control or Nbea KO), both cells were whole-cell patch clamped, the presynaptic cell was stimulated, and responses were measured in the presynaptic (autaptic) and the postsynaptic (heterosynaptic) cell. Data for mean autaptic responses are shown in the middle histogram, and data for the mean heterosynaptic responses are shown in the right histogram. Genotype combinations (presynaptic cell/postsynaptic cell) are given below the histograms. Error bars indicate SEM. The numbers of cells analyzed are given in/above the histogram bars (**, $\mathrm{P}<0.01 ;{ }^{* * *}, \mathrm{P}<0.001$ in Student's $t$ test). 
$3 \mu \mathrm{M} \gamma$-aminobutyric acid (GABA), or $100 \mu \mathrm{M} N$-methyl-Daspartate (NMDA; Fig. 3, A-G; and Table S1). The same pattern was seen in glutamatergic and GABAergic Nbea KO cells, with defects of similar extent $(\sim 65 \%)$, and the same reductions in responses to glutamate, kainate, and GABA were observed in high-density cultures (Fig. S2, A-F; and Table S1). Nbea expression starts at DIV3 and increases progressively during development in vitro (Fig. S2 G). Unlike neurons from DIV11-15, Nbea KO neurons at DIV3-4 did not show impaired responses to exogenously applied receptor agonists (Fig. S2, H and I). As neurons at DIV3-4 do not have functional synapses, these findings indicate that the phenotype of Nbea $\mathrm{KO}$ neurons appears as neurons mature and form synapses and that the defective synaptic transmission upon Nbea KO is caused by severe postsynaptic transmitter receptor defects. At the ultrastructural level, synapses of Nbea KO hippocampal and neocortical neurons showed $12-26 \%$ reductions in the number of total and docked SVs and in the size of the active zone and postsynaptic density (see Fig. 4). However, these subtle morphological defects do not appear to cause detectable functional defects in presynapses of Nbea KO neurons (see Discussion; Figs. 1-3).

To distinguish synaptic and extrasynaptic NMDA receptors in autaptic cultures, we first measured the response to exogenous NMDA application followed by blockade of synaptic NMDA receptors by applying a $0.33-\mathrm{Hz}$ train of 100 stimuli in the presence of the irreversible open-channel blocker MK-801 and subsequently assessed the cellular response to a second exogenous NMDA application. In this regimen, synaptic NMDA receptors are selectively blocked by MK-801, and the ratio between the second and the first response to exogenous NMDA application reports the ratio of synaptic versus extrasynaptic NMDA receptors. To ensure that the measured NMDAmediated currents, after the $0.33-\mathrm{Hz} / 100$ stimuli protocol, were not affected by the length of the protocol and corresponding synaptic response rundown, we also used a 40-Hz/200 stimuli protocol. The two protocols yielded very similar data, which were pooled (Fig. 3, H and J). The ratios of responses to exogenously applied NMDA after and before MK-801 blockade obtained in control cells indicate that typically $\sim 80 \%$ of all functional NMDA receptors are synaptic (Fig. $3 \mathrm{~K}$ ). In contrast, Nbea KO neurons have much less synaptic NMDA receptors, whereas the surface density of extrasynaptic receptors is unaffected (Fig. 3, G-K; and Tables S1 and S2). To determine whether this effect is a consequence of presynaptic or postsynaptic defects, we simultaneously assessed the ratio of synaptic versus extrasynaptic NMDA receptors in heterologously paired glutamatergic hippocampal and GABAergic striatal neurons prepared from control and Nbea KO mice (Fig. $3 \mathrm{~L}$ and Table S2). We found that in these neuron pairs, the reduction of functional synaptic receptors only occurred in the Nbea KO neuron (Fig. $3 \mathrm{~L}$ and Table S2), excluding a major defect in presynaptic glutamate release. The synaptic release probability, which we estimated on the basis of the decay time course of the synaptic NMDA receptor current during the $0.33-\mathrm{Hz}$ train in the presence of MK-801, was similar between Nbea KO and control cells, further indicating that the synaptic release machinery is not affected by Nbea loss (Fig. 3 I).
The synaptic NMDA/AMPA response ratios were similar in Nbea KO and control cells (Fig. 3 I, inset). Moreover, the rectification indices and $\mathrm{I}-\mathrm{V}$ curves of AMPA responses, measured in paired recordings in microislands with two cells, were similar between Nbea KO and control neurons (Fig. S2, J and K), confirming that the relative abundance of the major GluA subunits is normal in the absence of Nbea and that the reduced glutamate responses in Nbea $\mathrm{KO}$ neurons are primarily caused by the loss of functional synaptic NMDA and AMPA receptors.

The effects of Nbea KO on evoked EPSC/IPSC amplitudes and on responses to agonists were rescued by reexpression of full-length Nbea, whereas a C-terminal Nbea segment showed no rescue activity (Fig. 5 and Table S3). The reintroduction of Nbea in Nbea KO neurons in these experiments resulted in a 1.8fold higher expression level of Nbea as compared with control neurons expressing GFP (Fig. S3, G and H). Because Nbea is a putative A kinase-anchoring protein, we tried to circumvent the loss of a possible A kinase-anchoring protein function and consequent defect in cAMP signaling in Nbea KO cells by treatment with the adenylate cyclase activator forskolin (10 $\mu \mathrm{M}$; DIV3-14), which only produced a small increase in evoked EPSC/IPSC amplitudes (Fig. 5, Q and R; and Table S1). These rescue data indicate that the Nbea KO phenotype is cell autonomous.

Dendritic and somatic Nbea localization and normal morphology of $\mathrm{Nbea} K \mathrm{~K}$ neurons

Because the Nbea-related protein LYST regulates the function of lysosomes and related organelles (Burkhardt et al., 1993; Zhao et al., 1994; Nagle et al., 1996; Introne et al., 1999) and the data described so far would be compatible with altered neuronal morphology and synapse numbers, we studied the morphology of Nbea KO neurons. Immunostaining showed that Nbea immunoreactivity accumulates in discrete compartments throughout somata and dendrites (Fig. 6). Somatic Nbea immunoreactivity is juxtaposed to the ER-Golgi intermediate compartment (ERGIC) and Golgi complex and colocalizes best with the SNARE protein Vti1A (Fig. 6, A and B). Dendritic puncta show highest overlap with recycling endosome markers (Rab11-GFP and transferrin receptor) but less overlap with markers for early endosomes (EEA1 and Rab5-GFP), mitochondria (Hsp70), secretory vesicles (neuropeptide Y [NPY]), lysosomes (Lamp1), or preand postsynaptic compartments (VAMP2 and PSD95; Fig. 6, E and F). The morphology of lysosomes (Fig. S3, I-K), the Golgi apparatus, and the ER (Fig. S4, A and B) was not altered in Nbea $\mathrm{KO}$ cells. This indicates that, unlike other BEACH domain proteins, Nbea does not control the endomembrane architecture of cells. Upon depolarization of neurons with solutions containing high potassium concentrations, Nbea immunoreactivity becomes more dispersed (Fig. S4 C). This was noticeable in somata but more prominent in dendrites, in which puncta became bigger and dimmer, whereas the cis-Golgi marker GM130 and the presynaptic marker VAMP2 remained unchanged (Fig. S4, D-I).

To study the effects of Nbea loss on synapse formation, we made use of antibodies to VGLUT1 and vesicular inhibitory amino acid transporter (VIAAT; Wojcik et al., 2004, 2006), which label glutamatergic and GABAergic presynapses, respectively, and to PSD95 and gephyrin (Schlüter et al., 2006; Fritschy et al., 
A
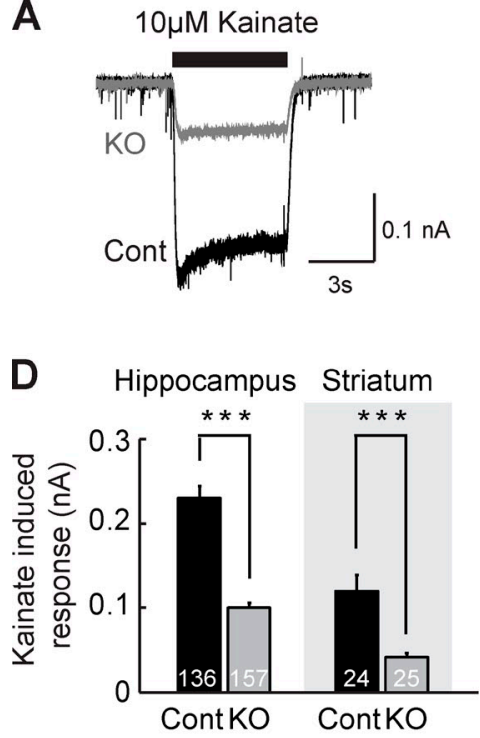

G

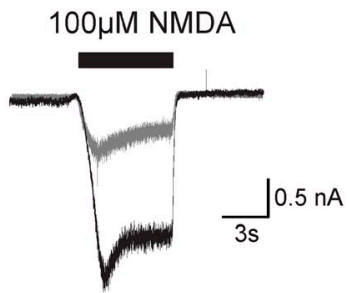

$\mathrm{H}$

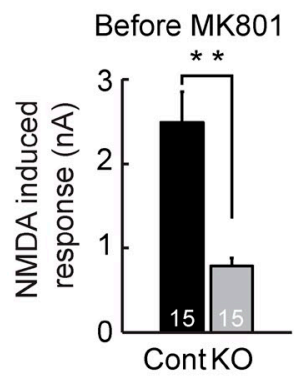

B

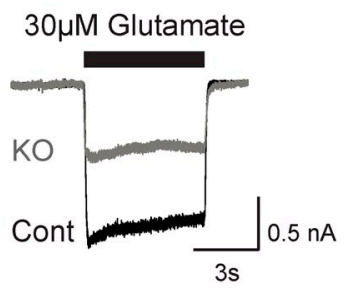

E
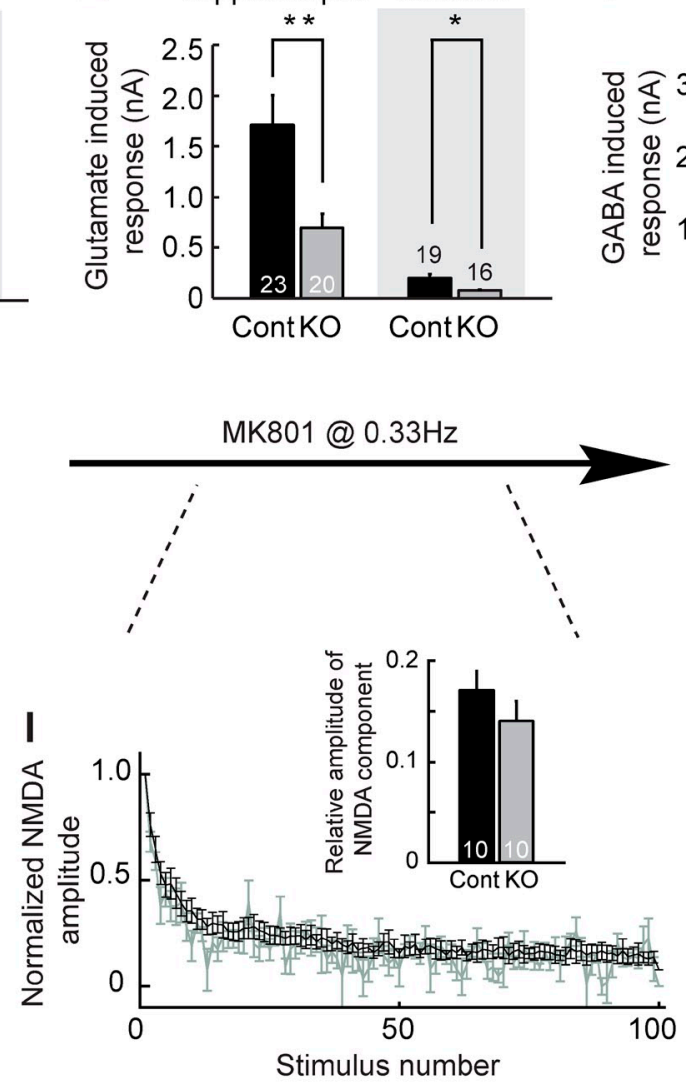

C

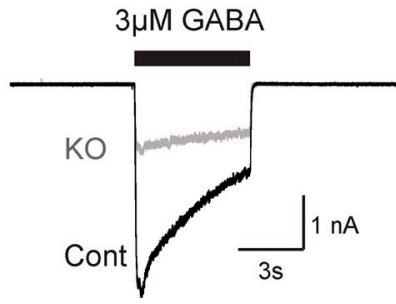

F Hippocampus Striatum

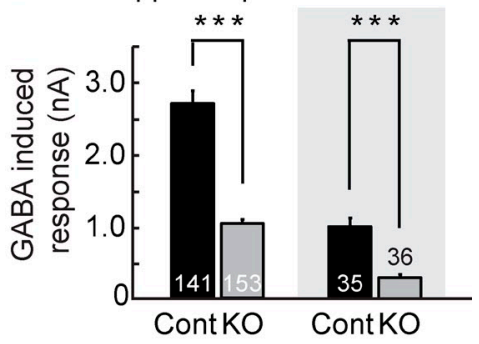

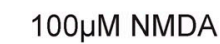

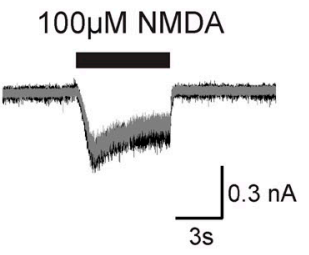

J After MK801

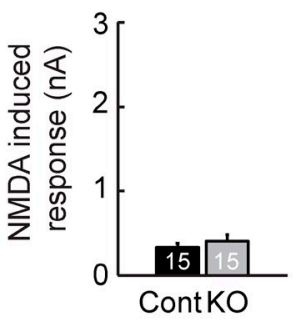

$\mathrm{K}$

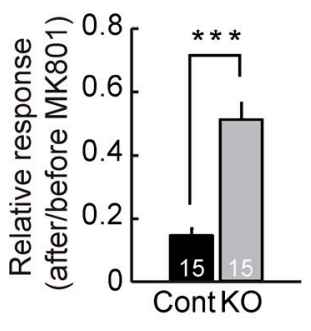

$\mathbf{L}$

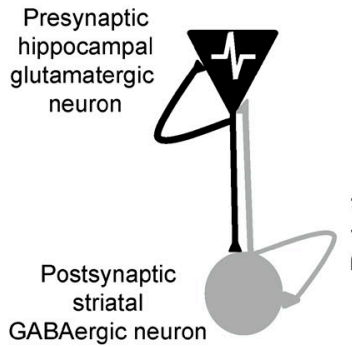

Hippocampus

Striatum

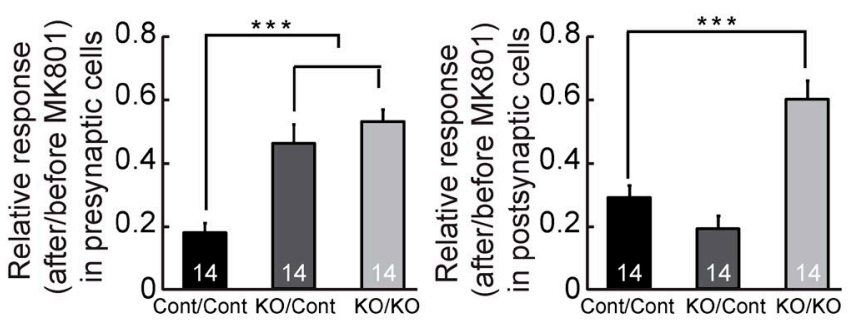

Presynaptic/Postsynaptic neurons

Figure 3. Reduced density of synaptic neurotransmitter receptors in Nbea KO neurons. (A-C) Traces of responses to exogenous $10 \mu M$ kainate $(A)$, $30 \mu \mathrm{M}$ glutamate (B), and $3 \mu \mathrm{M}$ GABA (C) in glutamatergic Nbea KO and control (Cont) neurons. (D) Mean amplitudes of responses to exogenous $10 \mu M$ kainate in hippocampal glutamatergic (left) and striatal GABAergic cells (right, on gray background) of control and Nbea KO mice. (E) Mean amplitudes of responses to exogenous $30 \mu \mathrm{M}$ glutamate in hippocampal glutamatergic (left) and striatal GABAergic cells (right, on gray background) of control and Nbea KO mice. (F) Mean amplitudes of responses to exogenous $3 \mu \mathrm{MGABA}$ in hippocampal glutamatergic (left) and striatal GABAergic cells (right, on gray background) of control and Nbea KO mice. (G) Example traces of responses to exogenous $100 \mu \mathrm{M} \mathrm{NMDA}$ in glutamatergic Nbea KO (gray) and control neurons (black) before (left) and after (right) stimulation with 100 stimuli at $0.33 \mathrm{~Hz}$ in the presence of MK-801 to block synaptic NMDA receptors. (H) Mean amplitude of responses to exogenous $100 \mu \mathrm{M}$ NMDA in glutamatergic Nbea KO and control neurons before stimulation with 100 stimuli at $0.33 \mathrm{~Hz}$ in the presence of MK-801 (see G). (I) Time course of depression of synaptic responses in glutamatergic Nbea KO (gray) and control neurons (black) upon stimulation with 100 stimuli at $0.33 \mathrm{~Hz}$ in the presence of MK-801 to block synaptic NMDA receptors (see G). Amplitudes were normalized to the first response. The inset shows the mean NMDA component relative to the mean AMPA component in the cells tested. The numbers of cells analyzed are given in the histogram bars. (J) Mean amplitude of responses to exogenous $100 \mu M$ NMDA in glutamatergic Nbea KO and control neurons after stimulation with 100 stimuli at $0.33 \mathrm{~Hz}$ in the presence of MK-801, i.e., after blockade of synaptic NMDA receptors (see G). (K) Ratio of NMDA-triggered EPSC 
A

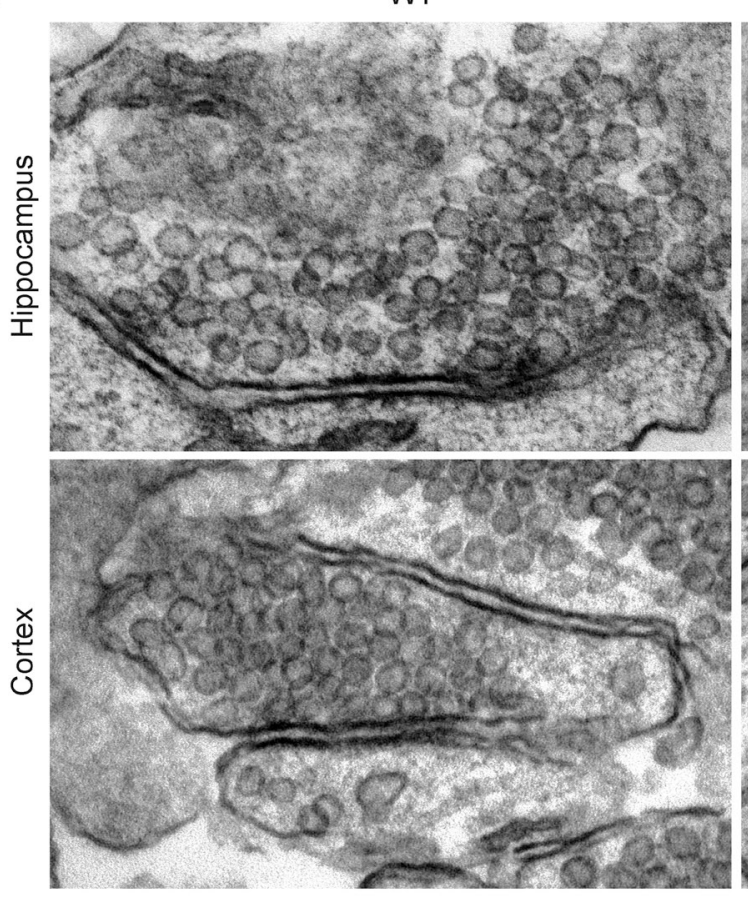

B Hippocampus Cortex

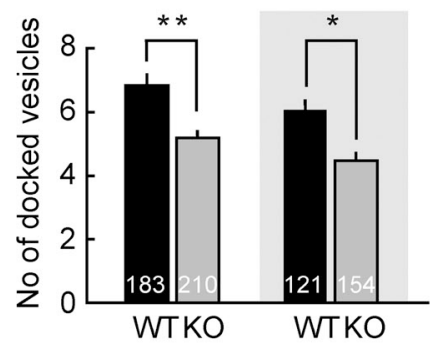

E Hippocampus Cortex

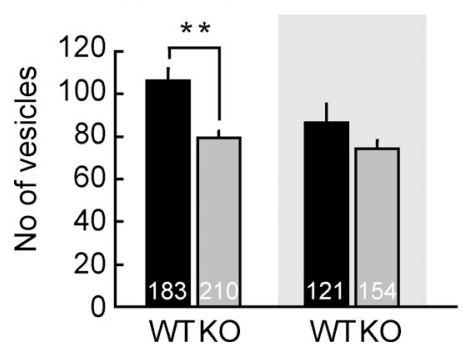

C Hippocampus Cortex
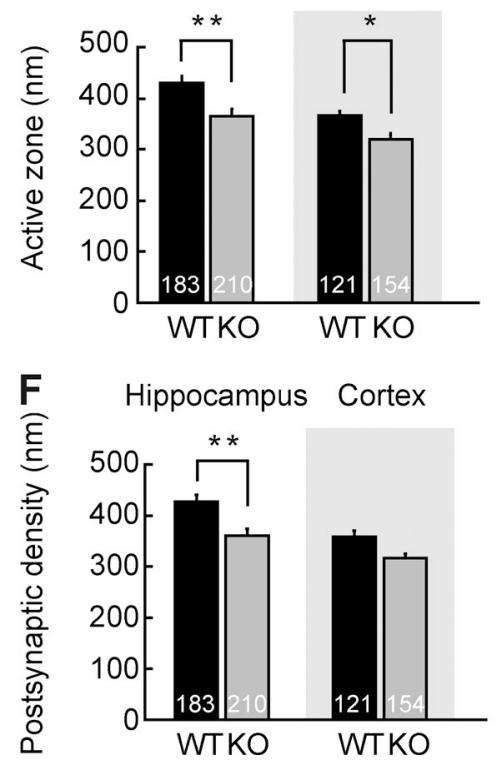

KO
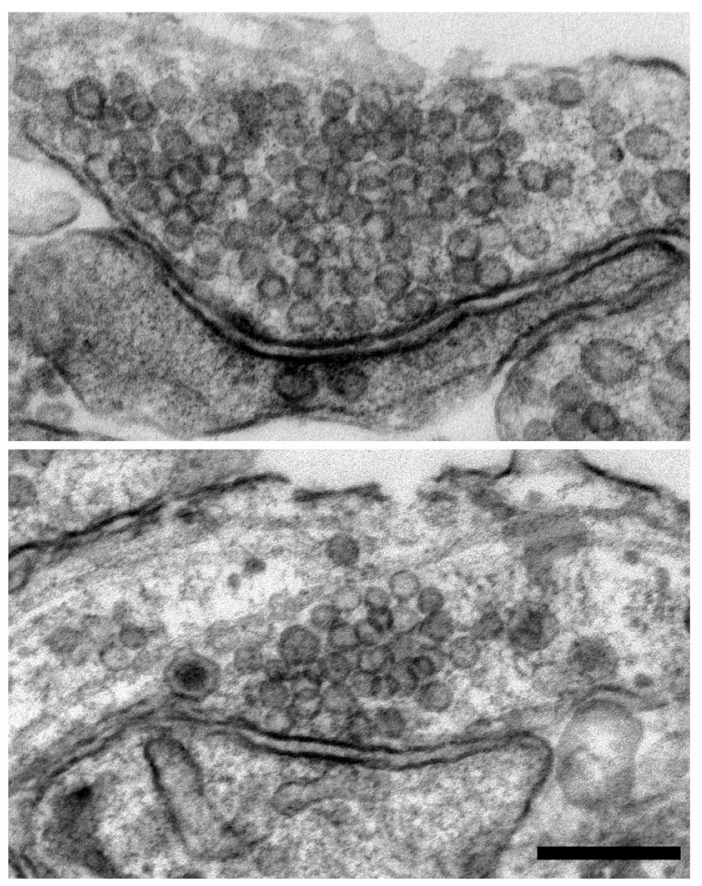

D Hippocampus Cortex

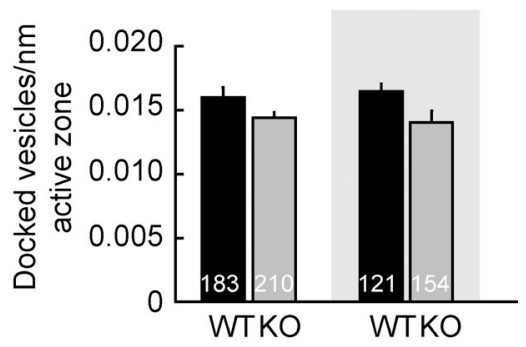

G Hippocampus Cortex

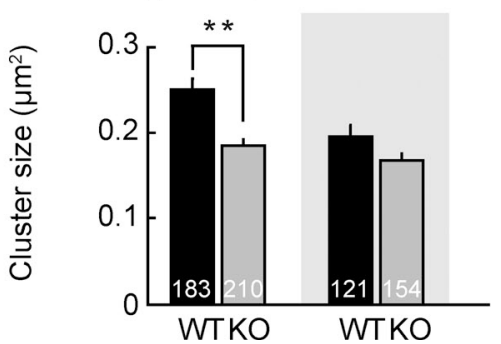

Figure 4. Minor perturbations in synaptic ultrastructure in Nbea KO neurons. (A) Electron micrographs of synapses in hippocampal (top) and cortical (bottom) high-density neuronal cultures (DIV14-15) from wild-type (WT) and Nbea KO mice. Bar, $200 \mathrm{~nm}$. (B) Quantification of the average number of docked SVs per synapse. (C) Quantification of active zone size. (D) Quantification of the average number of docked SVs per nanometer of active zone. (E) Quantification of the average total number of SVs per synapse. (F) Quantification of postsynaptic density size. (G) Quantification of the SV cluster size per synapse. Error bars indicate SEM. The numbers of synapses analyzed are given in the histogram bars (*, $\mathrm{P}<0.05 ;{ }^{*}, \mathrm{P}<0.01$ in Student's $t$ test).

amplitudes in glutamatergic Nbea KO and control neurons after versus before blockade of synaptic NMDA receptors by MK-801 (see G-J). (L) Recordings from pairs of neurons of different transmitter type on microislands as indicated in the diagram on the left. In each of the three genotype configurations tested (i.e., presynaptic glutamatergic cell control or Nbea KO and postsynaptic GABAergic cell control or Nbea KO), both cells were whole-cell patch clamped, and responses to exogenously applied NMDA (100 $\mu \mathrm{M})$ were measured in the presynaptic (autaptic) and the postsynaptic (heterosynaptic) cell before and after blockade of synaptic NMDA receptors (achieved by stimulating the presynaptic cell at $0.33 \mathrm{~Hz}$ with 100 stimuli in the presence of MK-801 (see G). Data for mean ratios of responses to exogenously applied NMDA before versus after blockade of synaptic NMDA receptors by MK-80 1 are shown for the presynaptic autaptic cell (middle histogram) and the postsynaptic heterosynaptic cell (right histogram). Genotype combinations (presynaptic cell/postsynaptic cell) are given below the histograms. Error bars indicate SEM. The numbers of cells analyzed are given in/above the histogram bars ${ }^{*}, \mathrm{P}<0.05 ;{ }^{* *}, \mathrm{P}<0.01 ;{ }^{* *}, \mathrm{P}<0.001$ in Student's $t$ test). 
A EPSC

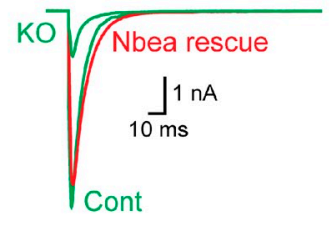

E

Glutamatergic neurons

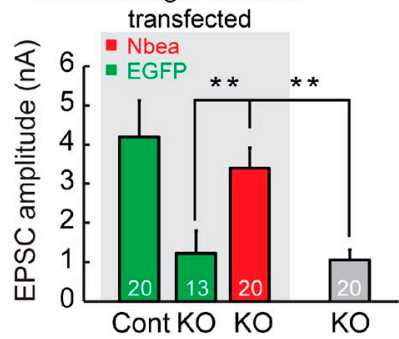

H GABAergic neurons

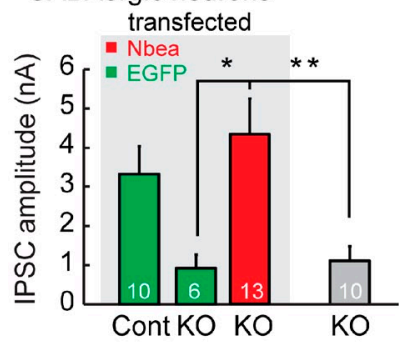

K

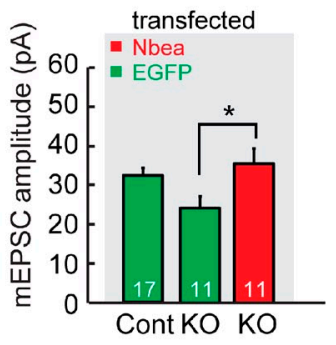

N Glutamatergic neurons

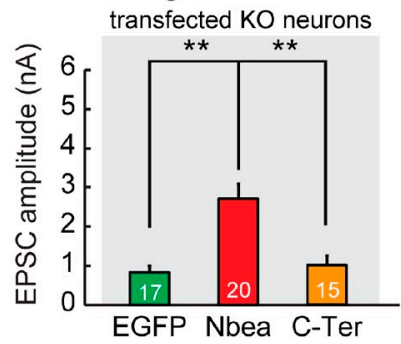

$\mathbf{Q}$

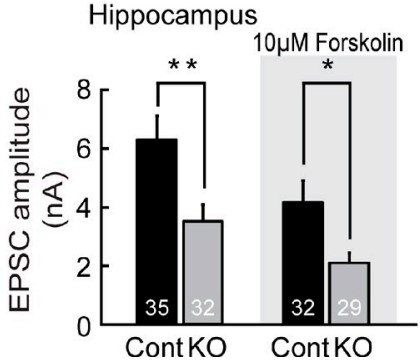

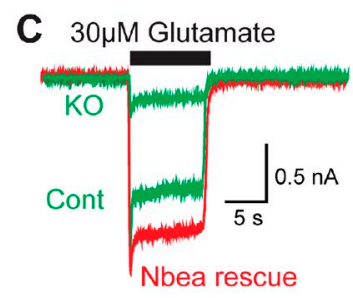

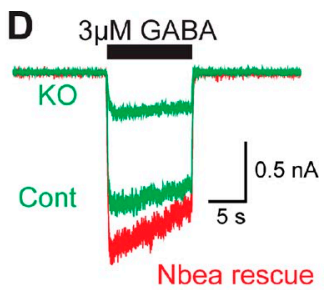

G
$\mathbf{F}$

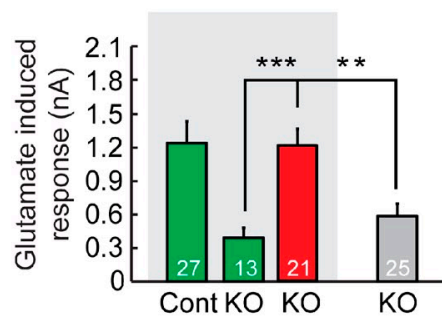

I

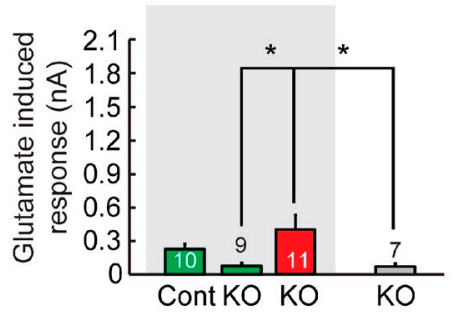

L

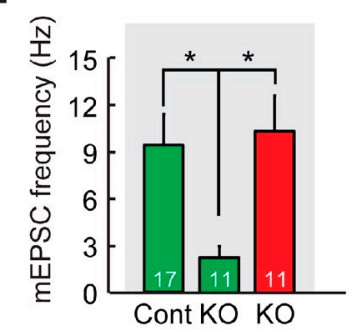

O

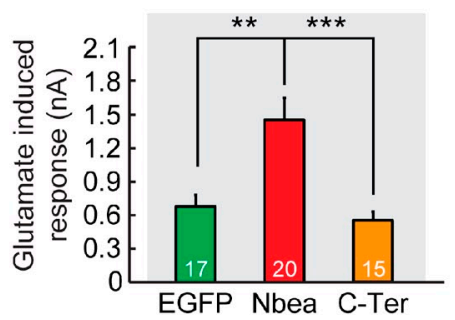

R Striatum

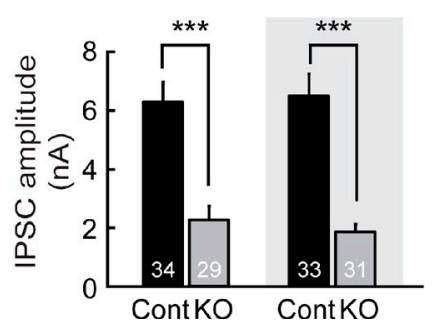

Figure 5. Nbea reexpression rescues the phenotypic defects of Nbea KO neurons. (A) Traces of depolarization-evoked EPSCs in glutamatergic Nbea KO neurons expressing EGFP, control (Cont) neurons expressing EGFP, and Nbea KO neurons expressing full-length Nbea (Nbea rescue). (B) Traces as in A but for IPSCs in GABAergic neurons. (C) Traces of responses to exogenous $30 \mu \mathrm{M}$ glutamate in glutamatergic Nbea KO neurons expressing EGFP, 
2008), which label glutamatergic and GABAergic postsynapses, respectively. The number of glutamatergic and GABAergic nerve terminals and the number of apposed pre- and postsynaptic structures were unaltered in Nbea KO cells (Fig. 7, A-E; and Table S4).

Next, we tested whether the reduced synaptic transmission in Nbea KO cells is caused by impaired cell maturation and dendrite development. We stained dendrites of fixed autaptic hippocampal neurons at DIV14 using an anti-MAP2 antibody and analyzed dendrite complexity by Sholl analysis (Sholl, 1953). Nbea KO neurons had longer and more complex dendrites than control neurons. The average number of dendrites was higher in Nbea KO neurons, and their dendrites were most complex at a distance of $30 \mu \mathrm{m}$ from their cell bodies, whereas dendrites of control cells were most complex at $22.5 \mu \mathrm{m}$ (Fig. S5, A and B). These results show that the reduced synaptic transmission in Nbea KO neurons is not caused by impaired dendrite growth and a concomitantly reduced synapse number.

\section{Reduced surface expression of transmitter} receptor proteins in $\mathrm{Nbea} \mathbf{K O}$ neurons

We next tested whether the reduced surface expression of functional neurotransmitter receptors in Nbea KO neurons is detectable at the protein level. We first used semiquantitative Western blotting to compare total receptor protein expression in Nbea $\mathrm{KO}$ and control neurons using whole-brain homogenates (embryonic day 18 [E18]) and DIV19 hippocampal cultures (Fig. 7, $\mathrm{F}$ and $\mathrm{G})$. Expressions of glutamate and GABA receptor subunits, and of all other pre- and postsynaptic proteins tested, were similar in Nbea KO and control preparations.

Next, we performed cell surface biotinylation assays on high-density hippocampal cultures (DIV19) to analyze surface expression of glutamate and $\mathrm{GABA}_{\mathrm{A}}$ receptor subunits. Nbea $\mathrm{KO}$ cells showed a $60 \%$ reduction in the cell surface level of GluA2/3 and a $40 \%$ reduction in the cell surface levels of GluA1, GluN1, GluN2A, GluK2/3, GABA $A_{A}-\gamma 2$, and $\mathrm{GABA}_{\mathrm{A}}-\alpha 1$ (Fig. 8, A and B). Surface expression of other proteins, such as neuroligin 1 or transferrin receptor, was unaffected or even slightly increased in Nbea KO cells. Also, the cell surface expression of the extrasynaptic $\mathrm{GABA}_{\mathrm{A}}$ receptor subunit $\mathrm{GABA}_{\mathrm{A}}-\alpha 5$ (Brünig et al., 2002) was slightly increased in Nbea KO cells, indicating that Nbea acts specifically on defined glutamate and $\mathrm{GABA}_{\mathrm{A}}$ receptors.

To confirm the reduced synaptic accumulation of neurotransmitter receptors in Nbea KO cells, we performed live immunostaining of surface-exposed receptors with antibodies to the extracellular N-terminal domains of GluA2 and $\mathrm{GABA}_{\mathrm{A}}-\gamma 2$.
GluA2-labeled neurons were fixed and colabeled for VGLUT1, whereas $\mathrm{GABA}_{\mathrm{A}}-\gamma 2-$ labeled neurons were fixed and costained for VIAAT. Nbea $\mathrm{KO}$ neurons showed a $60 \%$ reduction in the number of live-stained GluA2-positive puncta apposed to VGLUT1-positive puncta (Fig. 8, C and E; and Table S4), indicating that Nbea KO neurons form excitatory synapses normally but that the surface accumulation of receptors is severely impaired, especially in synapses. The remaining synaptic AMPA receptors appear to localize unequally to a subset of synapses so that a significant subfraction of synapses contain no or very few AMPA receptors and are postsynaptically nonresponsive. Along with the decreased surface levels of GluA2, Nbea KO cells showed increased GluA2/3 receptor subunit accumulation in the cell body, as indicated by stronger GluA2/3 immunostaining of cell somata after permeabilization of cells (Fig. $8 \mathrm{D}$ ). Such increased GluA2/3 receptor subunit accumulation was observed under basal conditions (Fig. 8 D) and after activity (i.e., in the presence of high potassium; not depicted). These findings are in accord with our biochemical data showing that the overall expression levels of AMPA receptor subunits are not changed in Nbea KO cells (Fig. 7, F and G) and indicate that AMPA receptor subunits are produced normally in Nbea KO cells but are then not transported properly to synapses. As was the case for AMPA receptors, the number of $\mathrm{GABA}_{\mathrm{A}}-\gamma 2$-positive puncta apposing VIAAT-positive puncta was reduced by $30 \%$ in glutamatergic and GABAergic neurons (Fig. 9 and Table S4). Thus, synaptic targeting of both AMPA and $\mathrm{GABA}_{\mathrm{A}}$ receptors is compromised in Nbea $\mathrm{KO}$ cells.

To test whether the loss of functional AMPA receptors in Nbea KO synapses is caused by altered receptor endocytosis, we kept cells in the absence or presence of high potassium (to accelerate receptor endocytosis), fixed them at different time points after live feeding with anti-GluA2 antibodies, and then immunostained the cell surface population of receptors without permeabilizing the cells and assessed the internalized population of receptors by permeabilizing the cells and detecting endocytosed anti-GluA2 antibodies. We found that GluA2 internalization was indistinguishable between control and Nbea KO cells (Fig. 8 F).

To obtain independent evidence for compromised receptor targeting in Nbea KO neurons and to identify the step in the secretory pathway that may be affected, we analyzed the levels of mature receptor subunits by assessing their sensitivity to endoglycosidase $\mathrm{H}$, which can be used as evidence for posttranslational modification in the Golgi apparatus. Nbea KO neurons showed 50\% reduced levels of maturely glycosylated GluA2/3

control neurons expressing EGFP, and Nbea KO neurons expressing full-length Nbea (Nbea rescue). (D) Traces as in C but for $3 \mu M$ GABA. (E) Mean evoked EPSC amplitudes in glutamatergic Nbea KO neurons expressing EGFP, control neurons expressing EGFP, and Nbea KO neurons expressing fulllength $\mathrm{Nbea}$ (Nbea rescue). Data from untransfected Nbea KO cells are shown in gray. (F) Mean amplitude of response to exogenous $30 \mu M$ glutamate in glutamatergic Nbea KO neurons expressing EGFP, control neurons expressing EGFP, and Nbea KO neurons expressing full-length Nbea (Nbea rescue). Data from untransfected Nbea KO cells are shown in gray. (G) Mean amplitude of response to exogenous $3 \mu M$ GABA in glutamatergic Nbea KO neurons expressing EGFP, control neurons expressing EGFP, and Nbea KO neurons expressing full-length Nbea (Nbea rescue). Data from untransfected Nbea KO cells are shown in gray. (H) Data as in $E$ but for evoked IPSCs in GABAergic neurons. (I) Data as in $\mathrm{F}$ but for GABAergic neurons. (J) Data as in $G$ but for GABAergic neurons. (K) Data as in E but for mEPSC amplitude. (L) Data as in E but for mEPSC frequency. (M) Data as in $E$ but for ratios of responses to exogenous 100 pM NMDA before versus after MK-801 blockade of synaptic NMDA receptors. (N) Mean evoked EPSC amplitudes in glutamatergic Nbea $\mathrm{KO}$ neurons expressing EGFP, full-length Nbea (Nbea rescue), or the Nbea C-terminus only (C-Ter). (O) Data as in $\mathrm{N}$ but for mean responses to exogenous $30 \mu \mathrm{M}$ glutamate. (P) Data as in N but for mean responses to exogenous $3 \mu \mathrm{M}$ GABA. (Q) Mean evoked EPSC amplitudes in glutamatergic Nbea KO and control neurons before and after treatment with $10 \mu \mathrm{M}$ forskolin (gray background). (R) Data as in Q but for IPSCs in GABAergic cells. Error bars indicate SEM. The numbers of cells analyzed are given in/above the histogram bars $(*, P<0.05 ; * *, P<0.01 ; * * *, P<0.001$ in Student's $t$ test). 
A
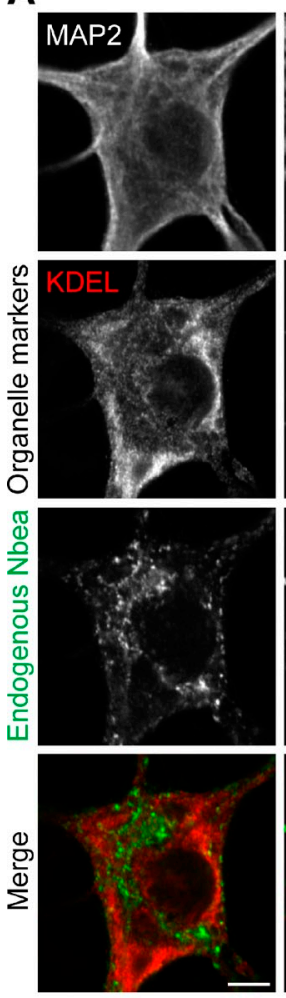

C
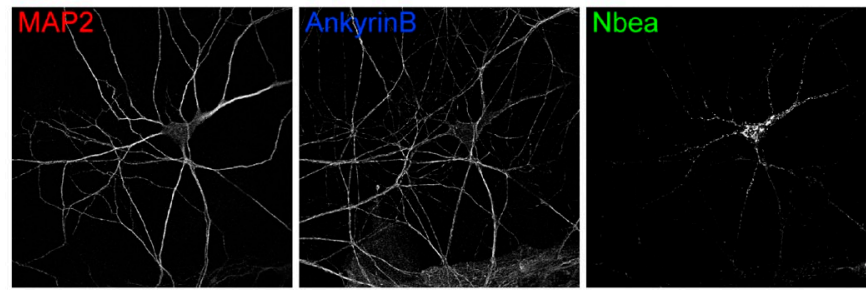

E Organelle markers Endogenous Nbea

D

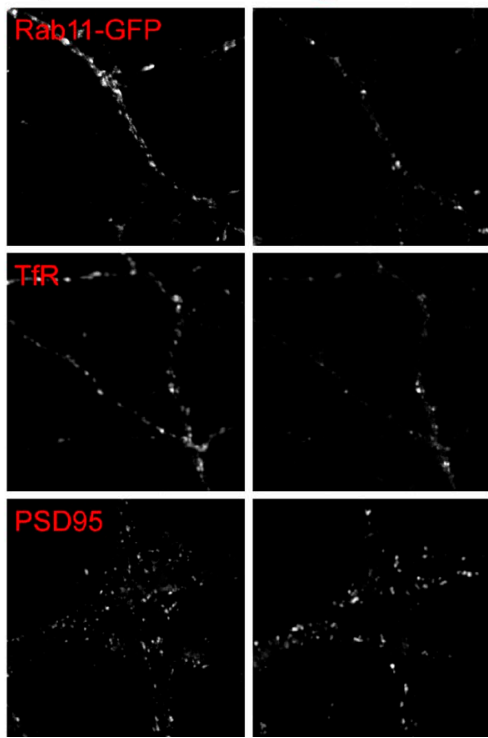

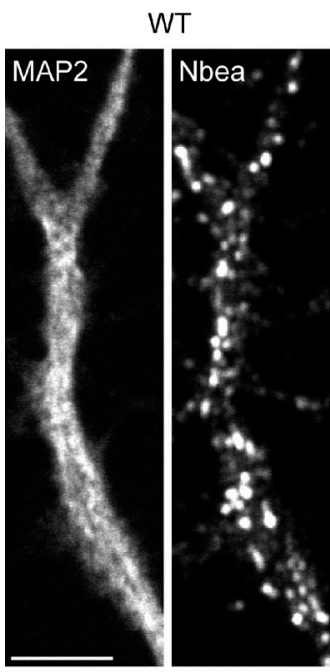
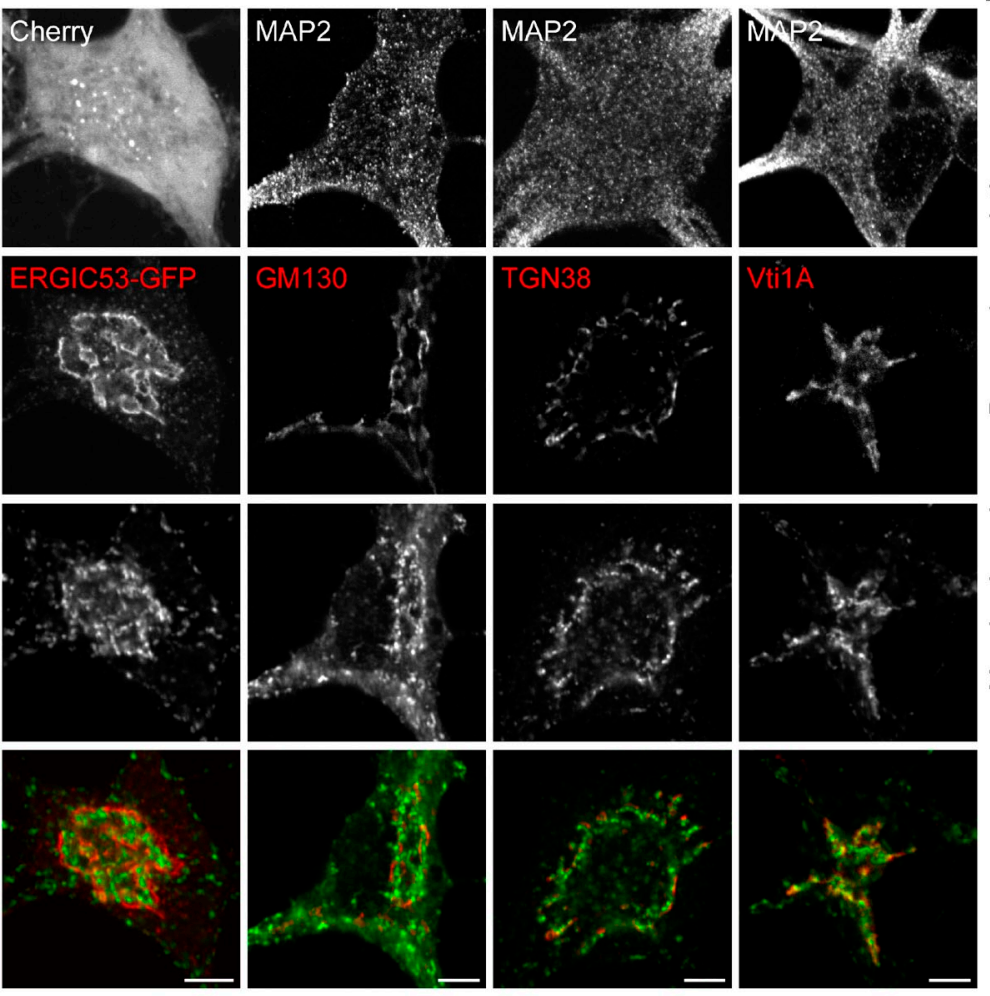

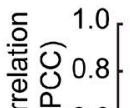
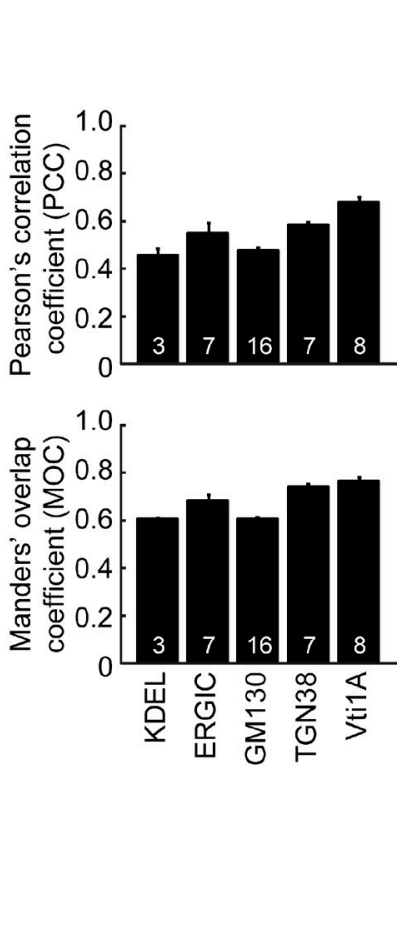

Merge

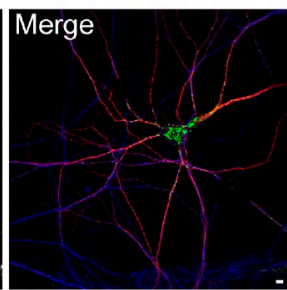

\section{F}

\section{B}
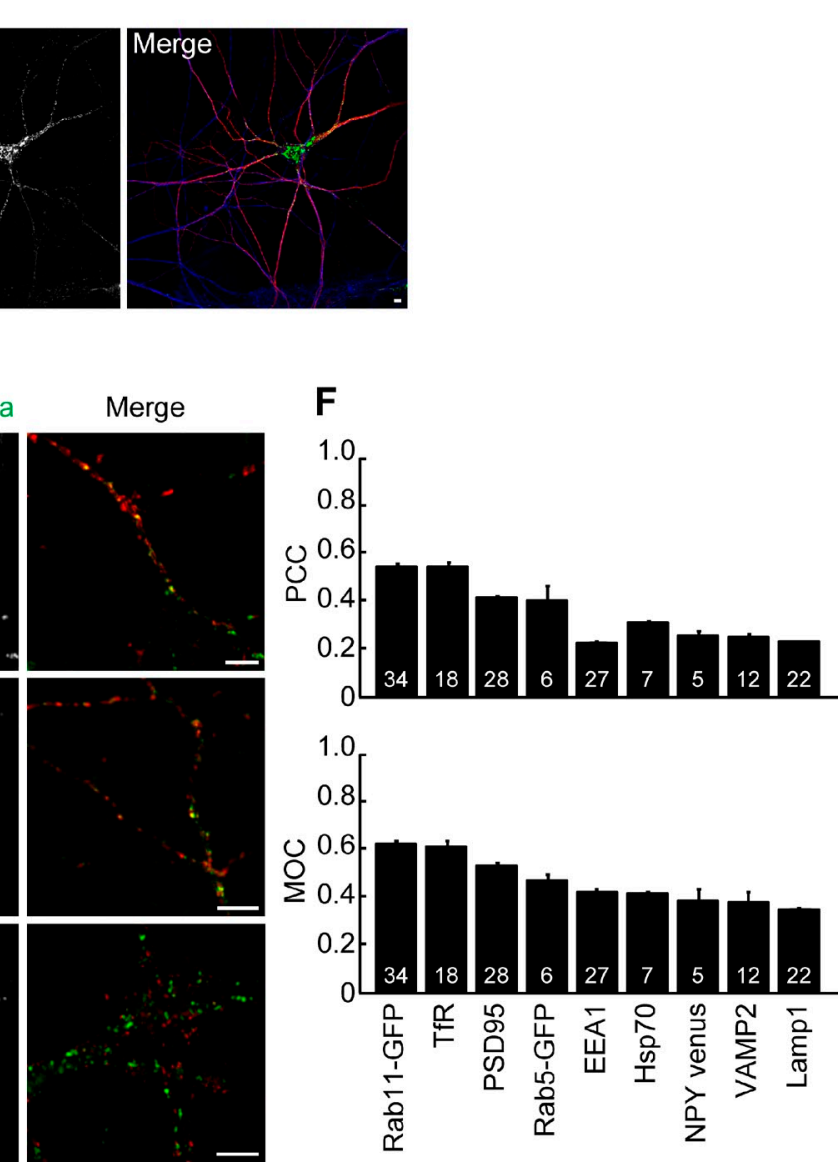

Figure 6. Nbea localization in WT neurons. (A) Somatic Nbea concentrates near the ERGIC and Golgi complex. WT hippocampal neurons (E 18) were cotransfected by a calcium phosphate precipitation method at DIV10-11 with plasmids encoding ERGIC53-GFP (ERGIC53) and mCherry (not depicted in the merge). At DIV14, cells were fixed and stained for endogenous Nbea with a rabbit polyclonal antibody (green) and for the markers indicated 
subunits, but not of GluK2/3, GABA $A_{A}-\alpha 1$, extrasynaptic GABA receptors $\left(\mathrm{GABA}_{\mathrm{A}}-\alpha 5\right)$, or neuroligin-1 (Fig. 10, $\mathrm{A}$ and $\left.\mathrm{B}\right)$. This indicates that Nbea deletion compromises GluA2/3 subunit trafficking from the ER to the Golgi apparatus or early within the Golgi apparatus, whereas other receptor subunits reach the Golgi apparatus and are arrested late within the Golgi apparatus or further downstream.

We finally immunolocalized various receptor subunits relative to the cis-Golgi marker GM130 and the ER marker KDEL receptor. Confocal images of samples immunostained in this manner showed a marked increase in somatic GluA2/3 puncta in Nbea KO neurons in comparison to control cells (Fig. S5 B and Table S4). Quantification of the number of somatic versus dendritic puncta revealed a centripetal redistribution of GluA2/3 in the Nbea KO neurons (Fig. S5 E and Table S4). Immunostaining of the $\mathrm{GABA}_{\mathrm{A}}-\gamma 2$ subunit and the GluN2A subunit revealed no such shift of receptors from dendrites to somata in Nbea KO neurons (Fig. S5, C and F and D and G, respectively; and Table S4), indicating differential regulation of AMPA, NMDA, and GABA receptor subunits by Nbea along the secretory pathway.

\section{Discussion}

Our study shows that Nbea is dispensable for cell-autonomous programs of neuronal development and synaptogenesis but required for normal synaptic transmission. Defective postsynaptic trafficking of the major ionotropic receptor types for excitatory and inhibitory neurotransmitters is the dominant consequence of Nbea KO. Our immunolabeling (Fig. 8, C-E; and Fig. 9) and electrophysiology data (Fig. 2 E and Fig. 3) show that postsynaptic receptors are specifically lost in Nbea KO neurons, but the overall expression levels of receptor subunits is not affected (Fig. 7, F and G). Analyses of their maturation and localization showed that the progress of AMPA, NMDA, GABA , and kainate receptors through the secretory pathway is differentially affected by Nbea KO.

Surprisingly, in view of previously published data, the present study on central nervous system neurons yielded primarily evidence for postsynaptic Nbea functions. Some indications for presynaptic defects in Nbea KO cells were observed at the ultrastructural level (Fig. 4), but several lines of evidence indicate that presynaptic defects are not the primary cause for the synaptic dysfunction upon Nbea KO. First, in neuron pairs in culture (Fig. 2, E), the synaptic phenotype of Nbea KO is exclusively observed if the responding neuron is Nbea deficient but not if the transmitter-releasing neuron lacks Nbea. Second, presynaptic short-term plasticity is unaffected in Nbea KO cells (Fig. 1, J and K). Third, the defects in synaptic transmission in Nbea KO neurons prevailed when calcimycin was used to trigger transmitter release (Fig. 2, A and B), indicating that defects caused by Nbea loss occur downstream of voltage-gated $\mathrm{Ca}^{2+}$ channel signaling, and vesicular and synaptic release probabilities were not or very weakly perturbed in Nbea KO neurons (Fig. 1 E and Fig. 3 I). Fourth, the FM1-43 loading experiments revealed no defects in the SV cycle or in the number of presynaptically active synapses (Fig. 2, C and D). Fifth, our Western blot analyses did not reveal altered expression of key presynaptic proteins in Nbea KOs (Fig. 7, F and G), which is different in the brainstem of Nbea KOs, where the expression levels of certain presynaptic proteins were found to be reduced (Medrihan et al., 2009). However, mIPSC frequencies were also reduced in Nbea KO brainstem neurons (Medrihan et al., 2009). This is compatible with a role of Nbea in postsynaptic receptor trafficking as described in the present study, assuming that some synapses in Nbea KO neurons contain less receptors, leading to reduced miniature PSC (mPSC) amplitudes (Fig. $1 \mathrm{H}$ ), whereas others contain very few or no receptors, causing an apparent reduction in mPSC frequencies (Fig. 1 I). Taking all of the aforementioned arguments into account, we conclude that Nbea does not have a major cell-autonomous presynaptic role in glutamatergic hippocampal and GABAergic striatal neurons, although we cannot exclude additional minor presynaptic roles of Nbea. The presynaptic changes in the Nbea $\mathrm{KO}$ at the ultrastructural level (Fig. 4) are rather small (0-30\%) and incongruent with the strong presynaptic defects that had been observed in Nbea KO neuromuscular junctions (Su et al., 2004). Thus, Nbea has different functions in glutamatergic and GABAergic synapses versus neuromuscular junctions. The effects on docked SVs and $\mathrm{SV}$ cluster size in Nbea KO cells that we observed might be a secondary effect of the chronically altered synaptic transmission in mutant neurons. Such structural changes occur upon chronic changes in activity and are in accord with other ultrastructural changes that were observed in the Nbea KO brain (Niesmann et al., 2011).

Several key regulators of synaptic glutamate receptor localization and function have been characterized (Malinow and Malenka, 2002; Bredt and Nicoll, 2003), such as CaMKII (Pettit et al., 1994), transmembrane AMPA receptor regulatory proteins (Tomita et al., 2005), Cornichon (Schwenk et al., 2009), or CKAMP44 (von Engelhardt et al., 2010).

(ER marker KDEL, cis-Golgi marker GM130, and trans-Golgi marker TGN38 or Vti 1A; dendritic marker MAP2 not depicted in the merge). All experiments were performed on mouse neurons, except for the analysis of TGN38, which was performed on rat neurons because of the lack of reactivity of the corresponding antibody in mouse cells. (B) Quantification of the colocalization of somatic Nbea with the different indicated markers using Pearson's correlation coefficient (PCC) and Manders' overlap coefficient (MOC). The numbers of cells analyzed are given in the histogram bars. (C) Dendritic Nbea localization. Cultured WT neurons were immunostained at DIV14 for Nbea, AnkyrinB, and MAP2. (D) Punctate localization pattern of Nbea in dendrites. Detail of a dendrite of a WT neuron costained for MAP2 (left) and Nbea (right). (E) Nbea-positive puncta show partial overlap with recycling endosomal and postsynaptic markers but low overlap with presynaptic and lysosomal markers. (top three images) DIV15 WT hippocampal neurons (cultured form E 18 embryos) were transfected at DIV10 by a calcium phosphate precipitation method with plasmids encoding Rab1 1-GFP and mCherry (not depicted in the merge) and stained after PFA fixation for Nbea. (middle three images) DIV15 WT hippocampal neurons (cultured form E18 embryos) were PFA fixed and stained for transferrin receptor (TfR) and endogenous Nbea. (bottom three images) DIV17 hippocampal neurons (cultured form E18 embryos) were fixed in methanol and stained for PSD95 and endogenous Nbea. (F) Quantification of colocalization of dendritic Nbea with different markers using Pearson's correlation coefficient and Manders' overlap coefficient. Error bars indicate SEM. The numbers of cells analyzed are given in the histogram bars. Bars, $5 \mu \mathrm{m}$. 
A

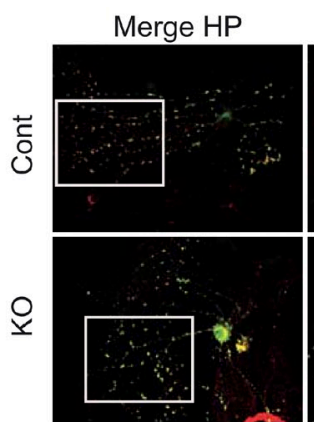

Merge HP

VGLUT1

PSD95
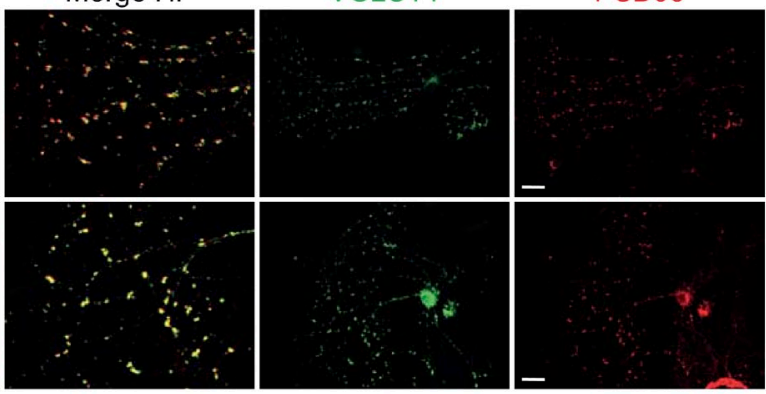

B

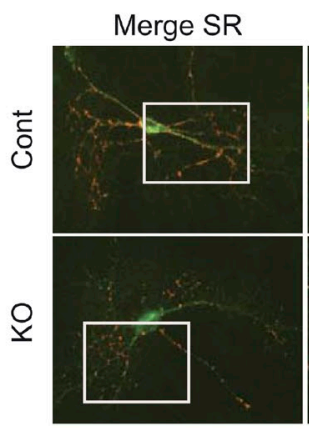

Merge SR

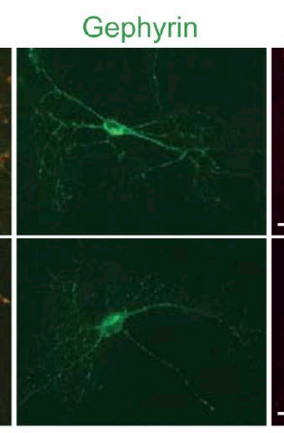

VIAAT
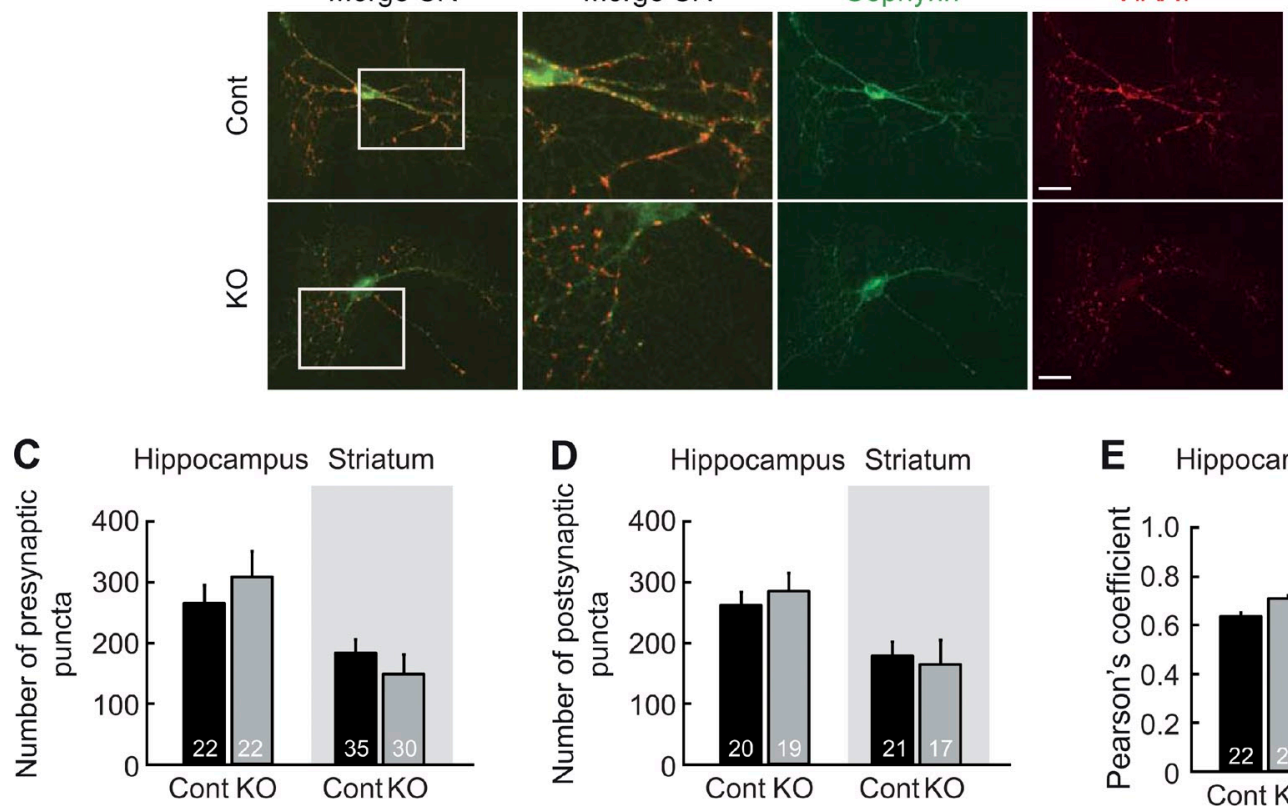

E Hippocampus Striatum

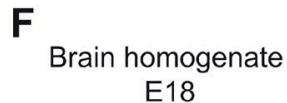

$\mathrm{kD}$

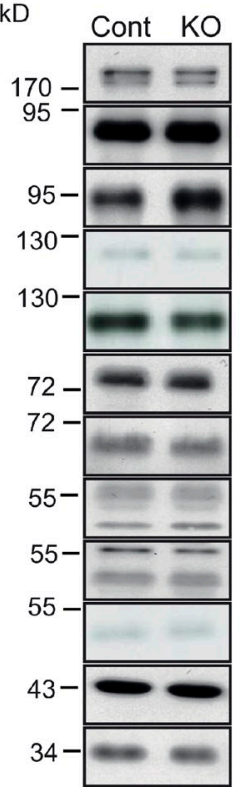

Cultured neurons DIV19

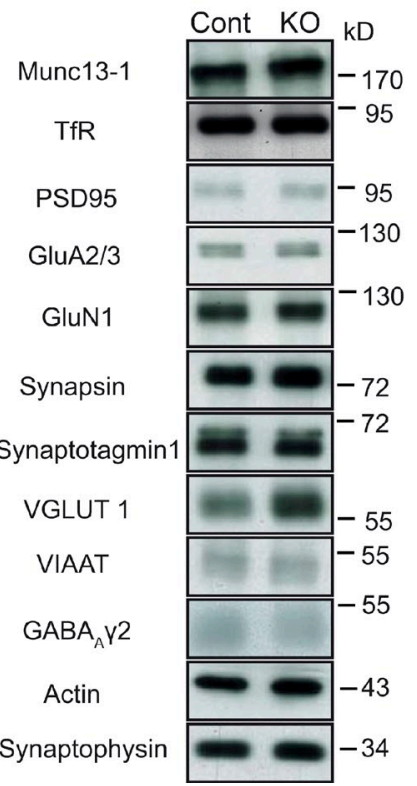

G

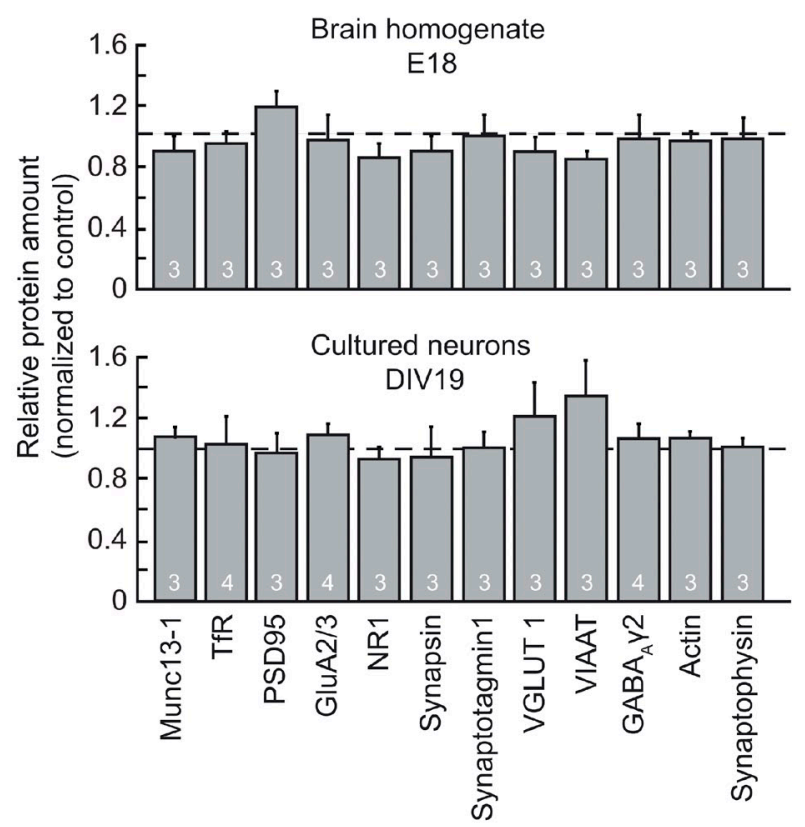

Figure 7. Normal synapse numbers and protein expression levels in Nbea KO neurons. (A) Double staining of control (Cont) and Nbea KO autaptic hippocampal (HP) neuron cultures at DIV15 using antibodies to markers of glutamatergic presynapses (VGLUT1) and postsynapses (PSD95). White boxes on the left depict the area enlarged in the next image to the right. (B) Double staining of control and Nbea KO autaptic striatal (SR) neuron cultures at DIV15 
Upon synaptic activity, AMPA receptor GluA1 and GluA2/3 subunits are differentially trafficked to synapses (Wenthold et al., 1996; Hayashi et al., 2000; Shi et al., 2001). Instead, Nbea loss equally affects the synaptic localization of GluA1 and GluA2/3 at rest (Fig. 8), indicating that Nbea acts upstream of the activitydependent bifurcation point of GluA1 and GluA2/3 trafficking. This is consistent with the fact that AMPA receptors accumulate early in the biosynthetic route and are partially immature upon Nbea KO.

Apart from exocytosis and endocytosis at synapses, transmitter receptors can move into and out of synapses by lateral diffusion (Bogdanov et al., 2006; Newpher and Ehlers, 2008). Based on electrophysiology (Fig. 3, G-J) and surface biotinylation experiments (Fig. 8, A and B), we present two lines of evidence indicating that Nbea deficiency has little effect on extrasynaptic receptors. Furthermore, receptor trafficking to the cell surface before synaptogenesis (Fig. S2 H) is not affected upon Nbea KO, whereas the levels of many receptor subunits present at synapses are reduced (Fig. 8, A-E; and Fig. 9). These data indicate a role of Nbea in targeting several major ionotropic neurotransmitter receptors directly to synapses. The regulation of receptor distribution between extrasynaptic and synaptic locations and of their activity-dependent redistribution between these locations appears to operate downstream of the initial Nbeadependent targeting step. Interestingly, a recent proteomic analysis (Lauks et al., 2012) revealed that Nbea binds SAP102, which interacts with glutamate receptors early in the biosynthetic route and regulates their targeting. This finding, along with the interaction of Nbea with the glycine receptor $\beta$ subunit (del Pino et al., 2011), further strengthens the notion that Nbea targets neurotransmitter receptors to synapses.

Nbea deletion affects at least four different ionotropic neurotransmitter receptor types, but different receptor types are affected differentially. AMPA receptors accumulate upstream of or early within the Golgi apparatus (e.g., in the ER), whereas NMDA, GABA $A$, and kainate receptors appear to accumulate late within or downstream of the Golgi apparatus (Fig. 10 and Fig. S5). The fact that AMPA receptors are not properly glycosylated and may become trapped at the ER level in Nbea KO cells indicates that the earliest action of Nbea in the biosynthetic pathway is at the level of ER exit, e.g., in a quality control mechanism that ensures that only properly assembled multimeric protein complexes leave the ER. The effect of Nbea KO on the trafficking of $\mathrm{GABA}_{\mathrm{A}}$, kainate, and NMDA receptors indicates an additional role of Nbea in the transport of receptors to the synaptic plasma membrane. This latter role does not seem to involve effects on the synaptic targeting of receptor scaffolding proteins, such as PSD95 and gephyrin, whose localization is unaffected by Nbea loss (Fig. 7, A-E).

\section{Materials and methods}

\section{Animals}

Two independent mouse lines were used in this study. The Nbea KO mice were generated using gene trap embryonic stem cell line RRK418, which was obtained from the International Gene Trap Consortium (Medrihan et al., 2009). The mice from the Cooke laboratory were generated as a control transgenic mouse line in the course of studying $h G H$ (human growth hormone) gene expression, using a minimal promotorless $h G H$ genomic fragment. By coincidental insertion of this transgene into intron 1 of the Nbea gene, the Nbea gene was rendered dysfunctional (Su et al., 2004). Central aspects of the synaptic phenotype, i.e., glutamate responsiveness, were tested and confirmed in both lines. Most of the other electrophysiological, morphological, and biochemical analyses were performed in the laboratory of J.S. Rhee using the mouse line generated by the laboratory of M.W. Kilimann (Medrihan et al., 2009). The ultrastructural analyses (Fig. 4 and Fig. S4 A), analyses of the subcellular localization of Nbea (Fig. 6), analyses of the developmental expression pattern of Nbea (Fig. S2 G), analyses of lysosomes (Fig. S3, I-K), analyses of ER, Golgi apparatus, and transferrin receptors using confocal microscopy (Fig. S4 B), analyses of Nbea levels in rescued neurons (Fig. S3, D-H), analyses of changes in Nbea distribution upon high potassium stimulation (Fig. S4, C-I), and analyses of glutamate responses in high-density cultures (Fig. S2, A and D) were performed in the laboratory of $M$. Verhage using the mouse line generated by the laboratory of N.E. Cooke (Su et al., 2004). For rat neuronal cultures, used for colocalization experiments of $\mathrm{Nbea}$ with the trans-Golgi marker TGN38, early endosome marker EEAl, and lysosomal marker Lamp1, newborn postnatal day 0-1 (PO-P1) pups from pregnant female Wistar rats were used (Harlan; Charles River).

\section{DNA constructs}

The full-length Nbea cDNA clone was generated from fragments of a yeast two-hybrid mouse brain cDNA library (catalogue no. ML408AH; Takara Bio Inc.) and from a partial image clone (mKIAA1544; Kazusa) using PCR and standard cloning techniques. This clone was used to generate the Nbea-IRES ${ }_{2}$ EGFP construct, which is based on pIRES ${ }_{2}$ EGFP (Takara Bio Inc.). pEGFP and pmCherry plasmids were obtained from Takara Bio Inc. The ERGIC53-GFP plasmid was donated by B. Kleizen (Utrecht University, Utrecht, Netherlands), the Rab5-GFP and Rab 1 1-GFP vectors were a gift from B. Soennichsen (Cenix BioScience, Dresden, Germany), and the venusNPY construct was a gift from A. Miyawaki (Institute of Physical and Chemical Research, Wako-City, Saitama, Japan).

\section{Cell culture and transfection}

Microisland and high-density cultures of hippocampal and striatal neurons were prepared and cultured as described previously (Jockusch et al., 2007; Burgalossi et al., 2012). In brief, astrocytes for microisland cultures were obtained from mouse cortices from PO WT animals using digestion with $0.25 \%$ trypsin (Gibco) for $20 \mathrm{~min}$ at $37^{\circ} \mathrm{C}$. The cells were plated in T75 culture flasks in DMEM medium (Gibco) containing 10\% FBS (PAA) and penicillin/streptomycin (Gibco). The medium was exchanged the day after plating, and cells were allowed to grow for 7-10 d. After this, cells were collected from the flask using trypsin digestion and plated at a density of 12,000 cells/well on 32-mm coverslips. The coverslips used for microisland cultures were first coated with agarose (Sigma-Aldrich) and then with

using antibodies to markers of GABAergic presynapses (VIAAT) and postsynapses (gephyrin). White boxes in the left depict the area enlarged in the next image to the right. (C) Average number of presynaptic puncta in cultured autaptic hippocampal (VGLUTI positive) and striatal neurons (VIAAT positive, gray background) from control and Nbea KO mice. The numbers of cells analyzed are given in the histogram bars. (D) Average number of postsynaptic puncta in cultured autaptic hippocampal (PSD95 positive) and striatal neurons (gephyrin positive, gray background) from control and Nbea KO mice. The numbers of cells analyzed are given in the histogram bars. (E, left) Degree of apposition between VGLUT1 and PSD95 in cultured autaptic hippocampal neurons from control and Nbea KO mice. (right) Degree of apposition between VIAAT and gephyrin in cultured autaptic striatal neurons (gray background) from control and Nbea KO mice. The numbers of cells analyzed are given in the histogram bars. (F) Examples of SDS-PAGE and Western blot analyses of the indicated proteins in E 18 brain homogenates and DIV 19 cultured hippocampal neurons from control and Nbea KO mice. TfR, transferrin receptor. (G) Quantification of SDS-PAGE and Western blot analyses of the indicated proteins in Nbea KO preparations. The dotted line represents the normalized control values for expression level of each protein in brain or neurons compared with the values for protein levels in neurobeachin KO preparations. Data are normalized to the control levels. The numbers of brains/cultures analyzed are given in the histogram bars. Error bars indicate SEM. Bars, $20 \mu m$. 


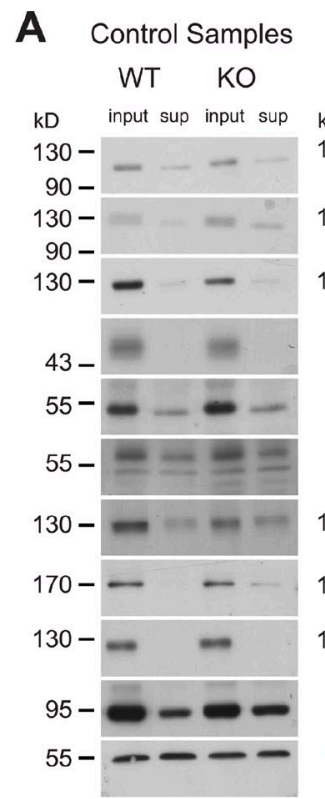

Biotinylated

B

Samples

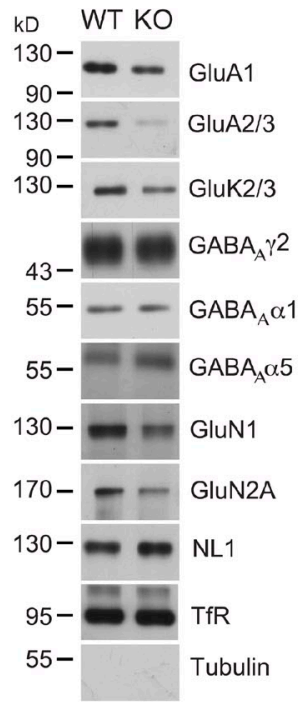

C Merge
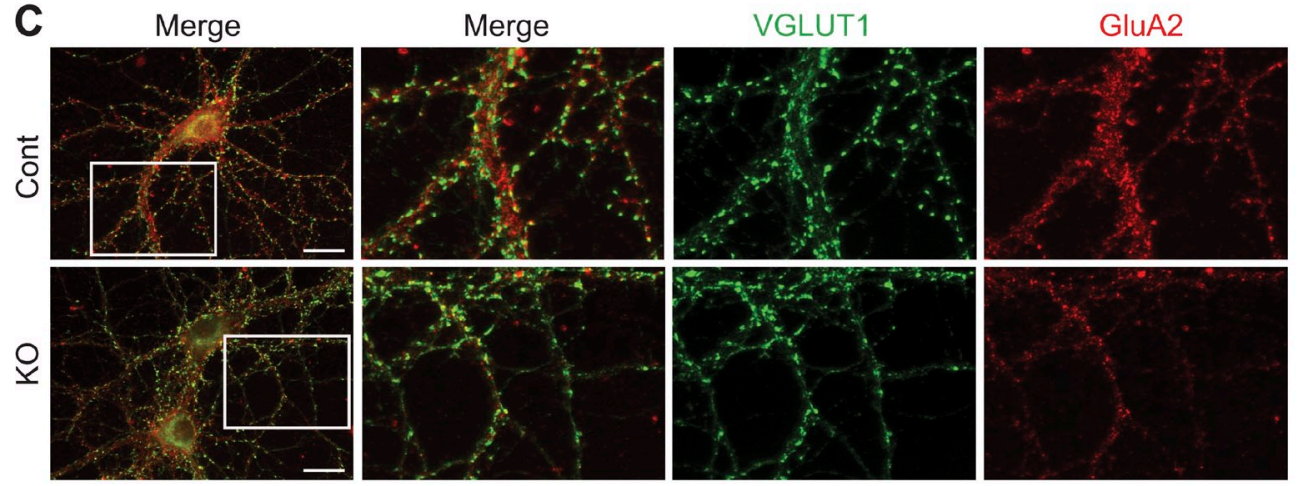

D Merge

Merge

GluA2/3

GluA2
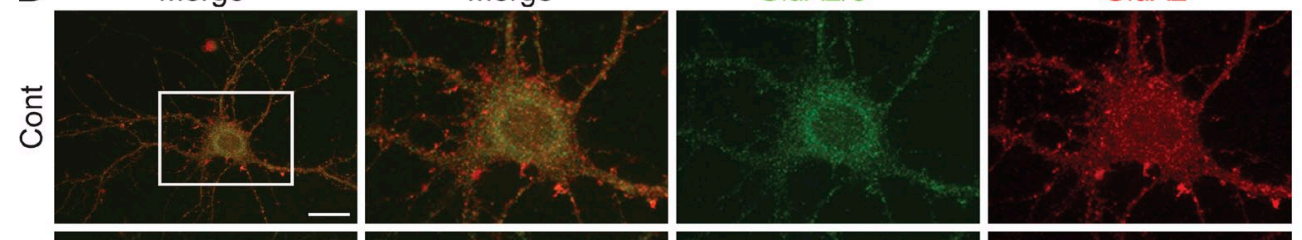

$\underline{0}$
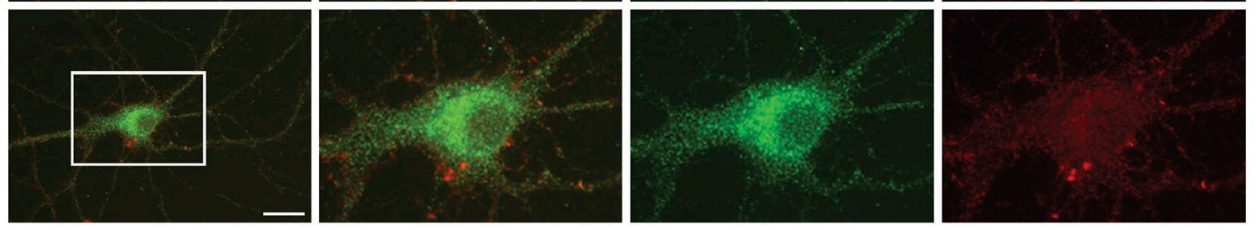

E

F
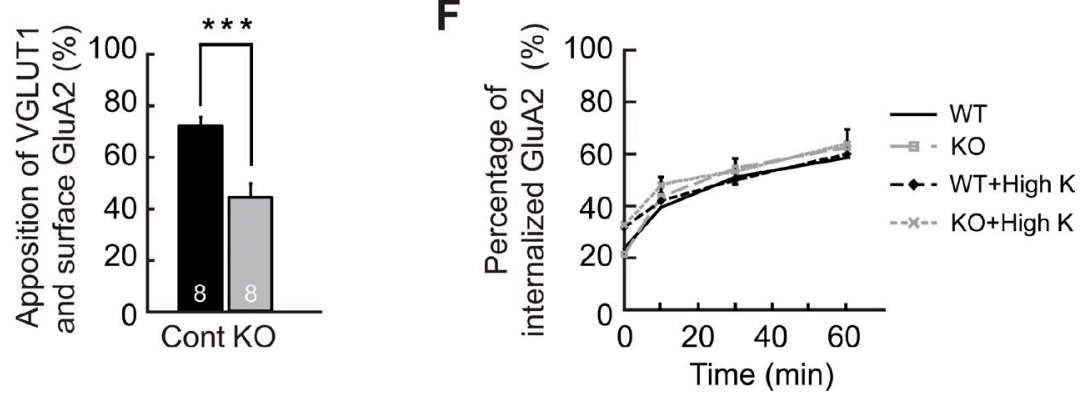

Figure 8. Impaired cell surface trafficking and synaptic targeting of multiple neurotransmitter receptors in Nbea KO neurons. (A) Biotinylation assays were performed on high-density DIV19 hippocampal neuron cultures from control (Cont) and Nbea KO mice to assess the surface expression of the proteins indicated. Fractions obtained in the assay were processed for SDS-PAGE and Western blotting for the indicated proteins. Immunolabeled bands were 
A Merge HP

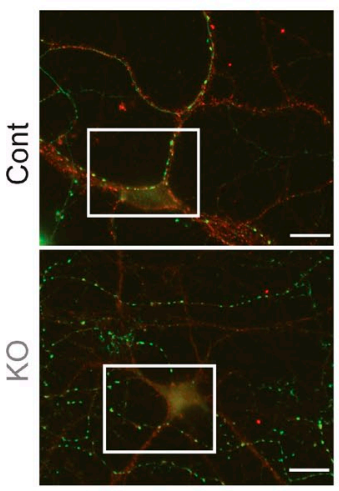

B

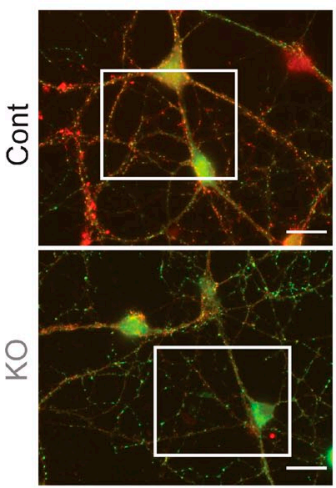

D

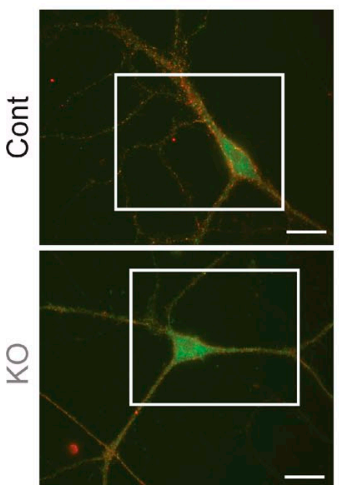

Merge HP

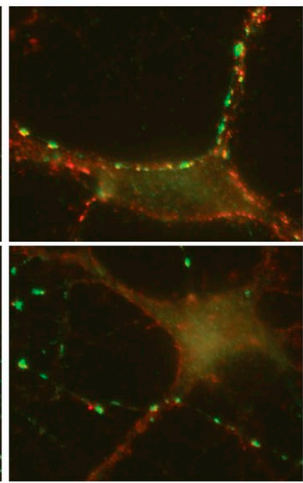

Merge SR

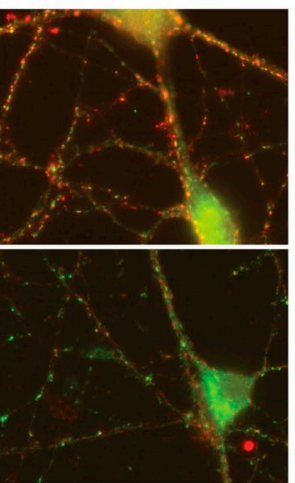

Merge SR

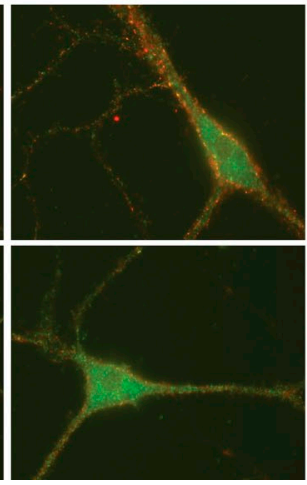

VIAAT

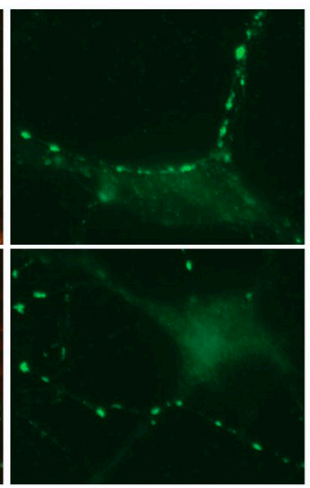

VIAAT

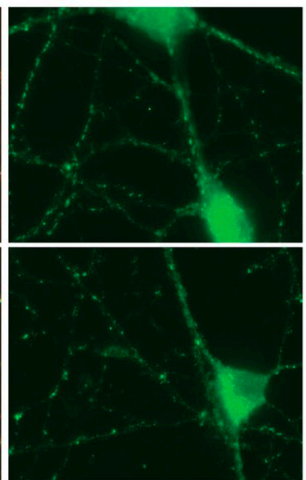

$\mathrm{GABA}_{\mathrm{A}} \mathrm{Y} 2$

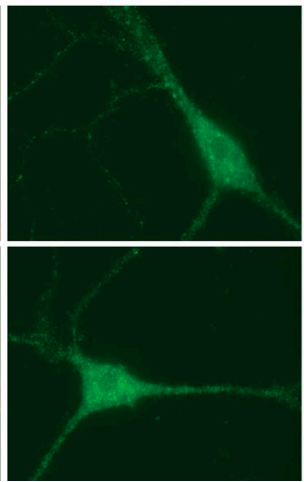

$\mathrm{GABA}_{\mathrm{A}}$ V2 surface

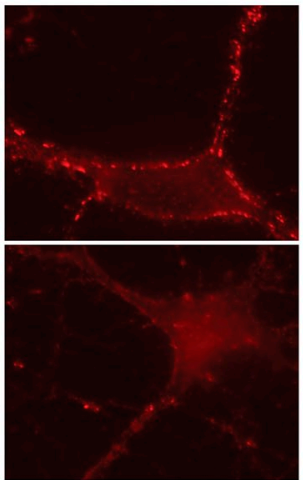

$\mathrm{GABA}_{\mathrm{A}} \mathrm{V} 2$ surface

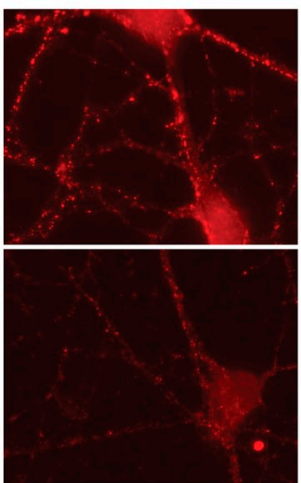

$\mathrm{GABA}_{A} \mathrm{Y} 2$ surface
C

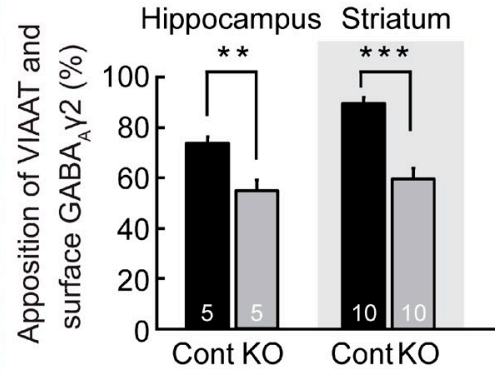

Figure 9. Reduced synaptic levels of $G A B A_{A}-\gamma 2$ in Nbea KO neurons. (A and $B$ ) Examples of immunofluorescence staining of surface $G A B A_{A}-\gamma 2$ and the presynaptic marker VIAAT in hippocampal (HP) neurons (A) and striatal (SR) neurons (B) of control (Cont) and Nbea KO mice. White boxes on the left indicate the enlarged area shown in the right images. (C) Quantification of the percentage of surface GABA $A_{A}-\gamma 2$ puncta apposing VIAAT in hippocampal and striatal neurons of control and Nbea KO mice. Error bars indicate SEM. The numbers of cells analyzed are given in/above the histogram bars $(* *, P<0.01 ; * * *, P<0.001$ in Student's $t$ test). (D) Examples of immunofluorescence double staining of control and Nbea KO neurons for surface

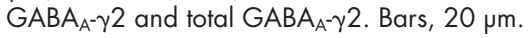

visualized by ECL. Input, total protein content before removal of the biotinylated fraction; sup, remaining supernatant after removal of the biotinylated fraction; affinity-purified biotinylated samples are shown on the right. TfR, transferrin receptor. (B) Quantification of surface expression of the indicated proteins in Nbea KO neurons. Data are from at least four independent experiments, except for $G A B A_{A}-\alpha 5$. Data are normalized to control levels. The dotted line represents the normalized control values for expression level of each protein in brain or neurons compared with the values for protein levels in neurobeachin KO preparations. (C) Surface staining of control and Nbea KO hippocampal neurons for GluA2 combined with staining for the presynaptic marker VGLUT1. White boxes on the left indicate the area enlarged in the right images. (D) Surface staining of control and Nbea KO hippocampal neurons for GluA2 combined with staining for total GluA2/3. White boxes on the left indicate the area enlarged in the right images. (E) Quantification of the ratios of surface GluA2 puncta apposing VGLUT1-positive presynapses in control and Nbea KO hippocampal neurons. (F) Endocytosis of GluA2. The graph shows the percentage of endocytosed GluA2 in cultured hippocampal wild-type (WT) and Nbea KO neurons over time under resting conditions and upon stimulation with high potassium solutions ( $n=7$ cells for all genotype/treatment combinations). Error bars indicate SEM. The numbers of cultures/cells analyzed are given in/above the histogram bars ${ }^{*}, \mathrm{P}<0.05 ;{ }^{* *}, \mathrm{P}<0.01{ }^{* * *}, \mathrm{P}<0.001$ in Student's $t$ test). Bars, $20 \mu \mathrm{m}$. 
Figure 10. Aberrant glycosylation of neurotransmitter receptors in Nbea KO neurons. (A) Samples of control (Cont) and Nbea KO hippocampal cultures (DIV19) that had either been left untreated (control) or had been digested with endoglycosidase $\mathrm{H}$ (Endo $\mathrm{H}$ ) or PNGase F (PNgase) and were then processed by SDS-PAGE and Western blotting for the indicated proteins. White lines indicate that intervening lanes have been spliced out. (B) Quantification of ratios between the levels of mature and immature proteins in Nbea KO cultures as assessed by endoglycosidase $\mathrm{H}$ sensitivity. For each sample, data were obtained by dividing the intensity of the band representing the endoglycosidase $\mathrm{H}$-insensitive protein fraction (i.e., higher molecular weight bands in the endoglycosidase $\mathrm{H}$-treated sample at the level of the bands detected in the respective untreated control samples) by the intensity of the band reflecting the endoglycosidase $\mathrm{H}$-sensitive protein fraction (i.e., lower molecular weight bands in the endoglycosidase $\mathrm{H}$-treated sample at the level of the band detected in the respective PNGase samples). Data are from at least four independent experiments (except for $G_{A B A_{A}-\alpha 5}$ ) and were normalized to the control levels. Error bars indicate SEM. The numbers of cultures analyzed are given in the histogram bars $\left({ }^{*}, \mathrm{P}<0.05\right.$ in Student's $t$ test). The dotted line represents the normalized control values for expression level of each protein in brain or neurons compared with the values for protein levels in neurobeachin KO preparations. (C) Model of the role of Nbea in neurotransmitter receptor trafficking. GLU, glutamate.

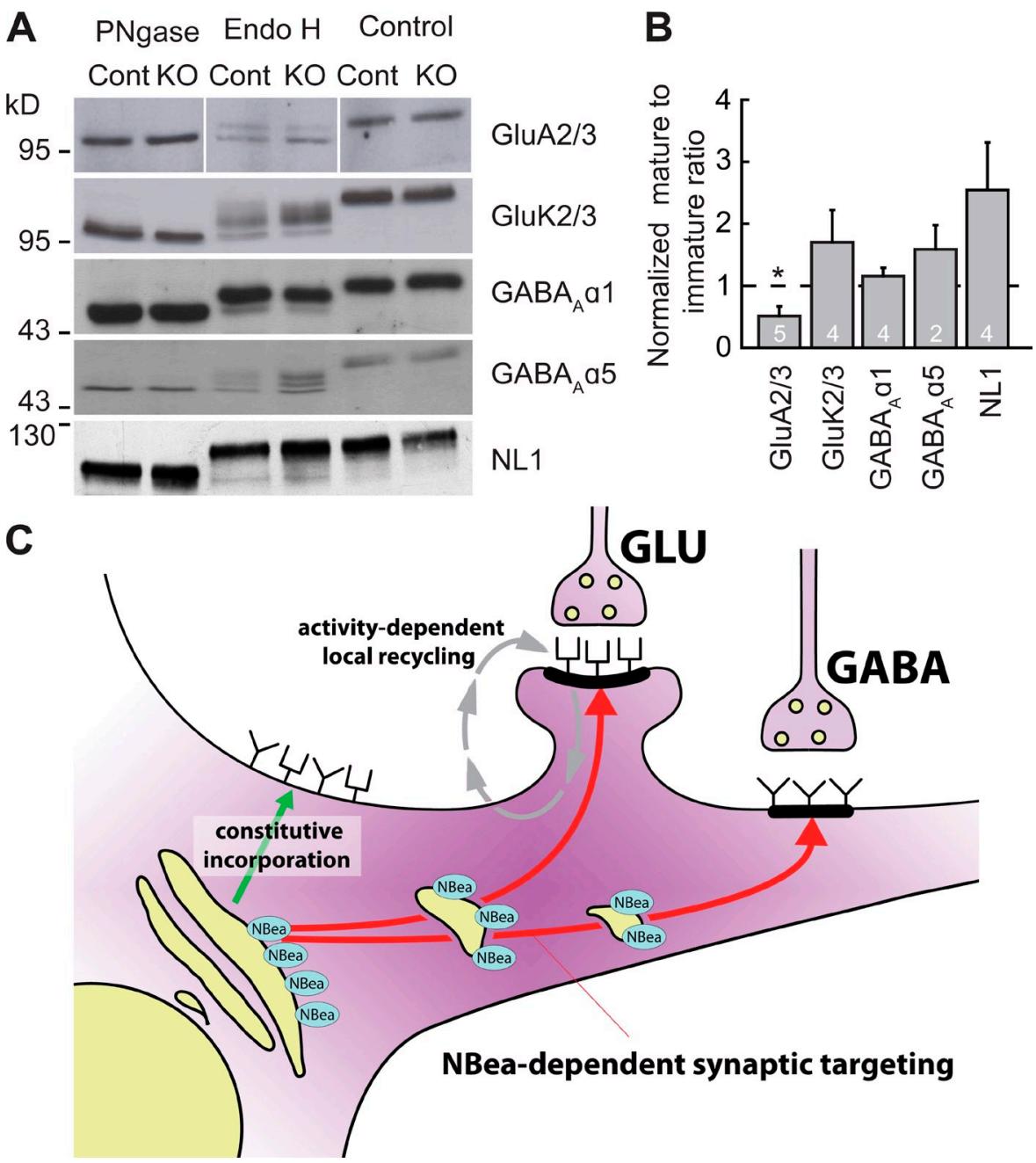

a coating solution containing poly-D-lysine (Sigma-Aldrich), acetic acid, and collagen $(\mathrm{BD})$ using a custom-made stamp to generate $200 \mu \mathrm{m} \times$ 200-pm substrate islands. Hippocampi, striata, and cortices from E18 mouse embryos were dissected free of meninges and separately collected in ice-cold HBSS (Gibco). They were incubated in papain solution containing $2 \mathrm{mg}$ cysteine, $10 \mathrm{ml}$ DMEM, $1 \mathrm{mM} \mathrm{CaCl}$, and $0.5 \mathrm{mM}$ EDTA, along with 20-25 U papain (Worthington Biomedical Corporation; $45 \mathrm{~min}$ for hippocampi and $60 \mathrm{~min}$ for striatum at $37^{\circ} \mathrm{C}$ ). After washing, cells were triturated and counted in a Fuchs-Rosenthal or Neubauer chamber. The cells were plated in prewarmed Neurobasal medium (Gibco) supplemented with B-27 (Gibco), GlutaMAX (Gibco), and penicillin/streptomycin at a density of 25,000 cells/well on 18-mm coverslips for high-density cultures or 4,000 cells/well on a 32-mm coverslip for microisland cultures. For the immunostaining experiments shown in Fig. 8, Fig. 9, and Fig. S5 and all biochemical experiments, neurons were plated on coverslips or dishes coated with a mixture of $30 \mathrm{\mu g} / \mathrm{ml}$ poly-D-lysine and $2 \mathrm{\mu g} / \mathrm{ml}$ laminin (Sigma-Aldrich) in Dulbecco's PBS (Gibco). For immunocytochemical experiments on hippocampal neurons, neurons were plated on glial feeder microislands (see as described previously in this paragraph). The cell cultures were transfected using calcium-phosphate precipitation as described previously (Köhrmann et al., 1999). In brief, to prepare the DNA/Ca ${ }^{2+}$ phosphate precipitate for two wells (of a 12-well plate), 3-5 $\mu \mathrm{g}$ DNA was diluted in water with $0.25 \mathrm{M} \mathrm{CaCl}_{2}$ and added in a dropwise manner to BES buffered saline (containing $50 \mathrm{mM}$ BES [N,N-bis[2-hydroxyethyl]-2aminoethanesulfonic acid], $280 \mathrm{mM} \mathrm{NaCl}$, and $1.5 \mathrm{mM} \mathrm{Na}_{2} \mathrm{HPO}_{4}$, $\mathrm{pH}$ 7.03), while vortexing at medium intensity. This transfection mixture was incubated for $23 \mathrm{~min}$ at RT in darkness before being mixed with serum-free medium and added to the cells. Cells were incubated for 10-15 min at RT, $5 \% \mathrm{CO}_{2}$, until a fine, sandy precipitate was visible under the microscope. Cells were then washed and placed back in the incubator with previously collected Neurobasal feeding medium. Autaptic neurons were transfected at DIV3-4, whereas the high-density cultures used for immunocytochemistry were transfected around DIV10. For heterologous pairs of cells on a single astrocyte microisland, glutamatergic (presynaptic) neurons were obtained from hippocampus, and inhibitory (postsynaptic) cells were obtained from striatum. Cell types in culture were identified based on their morphology and synaptic characteristics. For large, dense core vesicle labeling, neurons were transduced by a 10-h incubation with Semliki Forest virus encoding NPY-venus.

\section{Nbea antibody}

We used a recently characterized novel Nbea antibody (Lauks et al., 2012). The antibody was raised in rabbits against an antigen encoding Nbea residues 953-1,318. Antibodies were purified from antiserum using the same fusion protein coupled to cyanogen bromide-Sepharose (GE Healthcare) according to the instructions provided by the manufacturer.

\section{Electrophysiology}

Cells were whole-cell voltage clamped at $-70 \mathrm{mV}$ with an amplifier (Axoclamp; Molecular Devices) under the control of the Clampex program 10.1 (Molecular Devices). All analyses were performed using AxoGraph 4.1, AxoGraph X (AxoGraph Scientific), or Clampfit 10.2 (Molecular Devices). The cells were recorded between DIV10 and 19. EPSCs and IPSCs were evoked by depolarizing cells from -70 to $0 \mathrm{mV}$. The response to triggered release of the RRP was measured after application of $500 \mathrm{mM}$ hypertonic sucrose solution. mEPSCs and mIPSCs were recorded in the presence of $300 \mathrm{nM}$ tetrodotoxin (TTX). The extracellular solution contained $(\mathrm{mM}): 140$ $\mathrm{NaCl}, 2.4 \mathrm{KCl}, 10 \mathrm{Hepes}$, 10 glucose, $4 \mathrm{CaCl}_{2}$, and $4 \mathrm{MgCl}_{2}(320 \mathrm{mOsmol} /$ liter), $\mathrm{pH}$ 7.3. The patch-pipette solution for autaptic recordings contained (mM): $136 \mathrm{KCl}, 17.8$ Hepes, 1 EGTA, $4.6 \mathrm{MgCl}_{2}, 4 \mathrm{NaATP}, 0.3$ $\mathrm{Na}_{2} \mathrm{GTP}, 15$ creatine phosphate, and $5 \mathrm{U} / \mathrm{ml}$ phosphocreatine kinase (315-320 mOsmol/liter), pH 7.4. The patch-pipette solution for highdensity recordings contained $(\mathrm{mM})$ : 125 potassium-gluconic acid, $10 \mathrm{NaCl}$, 4.6 $\mathrm{MgCl}_{2}, 15$ creatine phosphate, $10 \mathrm{U} / \mathrm{ml}$ phosphocreatine kinase, and 
1 EGTA (300 mOsmol/liter), $\mathrm{pH} 7.3$. For experiments on the rectification indices and I-V curves of AMPA responses, the patch-pipette solution for paired recording of the postsynaptic cell contained (mM): 5 QX-314, 10 Hepes, 0.25 EGTA, $1 \mathrm{MgCl}_{2}, 4 \mathrm{MgATP}, 0.3 \mathrm{Na}_{2} \mathrm{GTP}, 8 \mathrm{NaCl}, 10$ tetraethylammonium- $\mathrm{Cl}, 15.5 \mathrm{CsCl}$, and 117.5 cesium methane sulphonate $(300 \mathrm{mOsmol} /$ liter), $\mathrm{pH} 7.4$. The series resistance was compensated by $\sim 60-80 \%$. All extracellular solutions were applied with a custom-built fast flow system consisting of an array of flow pipes controlled by a stepper motor that allows complete and rapid solution exchange with time constants of $\sim 30 \mathrm{~ms}$, except for the high-density recordings, in which glutamate was applied by pressure ejection from a glass electrode $(\sim 2.8 \mathrm{M} \Omega)$. Pressure was on for $20 \mathrm{~ms}$. All chemicals, except for TTX (Tocris Bioscience) and calcimycin (EMD Millipore), were purchased from Sigma-Aldrich.

\section{Electron microscopy}

Hippocampal and cortical high-density cultures of WT and Nbea KO mice (E 18) grown on glass coverslips were fixed (DIV14) for 45 min at RT with $2.5 \%$ glutaraldehyde in $0.1 \mathrm{M}$ cacodylate buffer, $\mathrm{pH} 7.4$. After fixation, cells were washed three times for $5 \mathrm{~min}$ with $0.1 \mathrm{M}$ cacodylate buffer $\mathrm{pH} 7.4$, postfixed for $2 \mathrm{~h}$ at RT with $1 \% \mathrm{OsO}_{4} / 1 \% \mathrm{KRu}(\mathrm{CN})_{6}$, washed, and stained with $1 \%$ uranyl acetate for $40 \mathrm{~min}$ in the dark. After dehydration through a series of increasing ethanol concentrations, cells were embedded in Epon and polymerized for $24 \mathrm{~h}$ at $60^{\circ} \mathrm{C}$. After polymerization of the Epon, the coverslip was removed by alternately dipping it in liquid nitrogen and hot water. Cells of interest were selected by observing the flat Epon-embedded cell monolayer under the light microscope and mounted on prepolymerized Epon blocks for thin sectioning. Ultrathin sections $(\sim 90 \mathrm{~nm}$ ) were cut parallel to the cell monolayer, collected on single-slot, Formvar-coated copper grids, and stained in uranyl acetate and lead citrate. Hippocampal and cortical synapses were randomly selected at low magnification using an electron microscope (1010; JEOL). For each condition, the number of docked SVs, total SV number, postsynaptic density and active zone length, and SV cluster surface (in nanometers squared) were measured on digital images taken at 100,000-fold magnification using analysis soffware (Soft Imaging System). The observer was blinded for the genotype. For all morphological analyses, we selected only synapses with intact synaptic plasma membranes with a recognizable pre- and postsynaptic density and clearly defined SV membranes. SVs were defined as docked if there was a distance of $0 \mathrm{~nm}$ between the SV membrane and the active zone membrane. In addition, we also took electron micrographs of the Golgi apparatus for qualitative analyses in each genetic condition. The active zone membrane was recognized as a specialized part of the presynaptic plasma membrane that contained a clear density apposed to the postsynaptic density and docked SVs. To obtain an estimate of the total SV pool, distances of undocked synaptic membranes to the active zone membrane were also included in our measurements. The SV cluster size indicates the size (perimeter) occupied by the total pool of SVs (docked and undocked) present in a synapse. In the case of hippocampal neurons, cells were cultured from six different WT and seven different KO mice (originating from four different litters). Cortical neurons were cultured from four different WT and five KO mice (originating from three different litters). Approximately 30 synapses were analyzed per culture stemming from one animal.

\section{Immunocytochemistry and FM1-43 labeling}

Neurons were fixed by incubation in 4\% PFA (Sigma-Aldrich) in PBS for $20 \mathrm{~min}$. Subsequently, they were permeabilized for $5 \mathrm{~min}$ in PBS containing $0.5 \%$ Triton X-100 followed by a 30 -min incubation in PBS containing $0.1 \%$ Triton $X-100$ and $2 \%$ normal goat serum to block nonspecific binding. The same solution was used for diluting antibodies. Neurons were incubated for $2 \mathrm{~h}$ in primary antibodies at RT or overnight at $4^{\circ} \mathrm{C}$, washed three times with PBS, and incubated in secondary antibodies for $1 \mathrm{~h}$. After an additional three washes, they were mounted in ProLong Gold (Invitrogen) or DABCO-Mowiol. All procedures were performed at RT. This protocol was followed for all standard immunocytochemistry, except for PSD95 immunostaining, in which cells were fixed by a 4-min methanol incubation at $-20^{\circ} \mathrm{C}(20 \mathrm{~min}$ in case of morphological analysis), and for EEA 1 immunostaining, which required a $30-\mathrm{min} 0.1 \%$ saponin permeabilization. Specific primary antibodies were used against ankyrinB (1:250; mouse monoclonal 2.20; Santa Cruz Biotechnology, Inc.), EEA1 (1:100; mouse monoclonal 14; BD), GABA- $\gamma 2$ (1:1,000; rabbit polyclonal; Abcam), gephyrin (1:1,500; mouse monoclonal 3B 11; Synaptic Systems), GluA2/3 (1:500; rabbit polyclonal; EMD Millipore), GluN2A 11:500; rabbit polyclonal; EMD Millipore), GM130 (1:1,500; mouse monoclonal 35; BD), KDEL receptor (1:100; mouse monoclonal 10C3; Stressgen), Lamp1 (1:100; mouse monoclonal LY1C6; Stressgen), Lamp1 (1:100; rat monoclonal 1D4B; Abcam), MAP2 (chicken polyclonal; 1:20,000 [Abcam] and 1:4,000 [Novus Biologicals]), MAP2 (1:1,000; mouse monoclonal AP20; EMD Millipore), mitochondrial Hsp70 (1:1,000; mouse monoclonal MA3028; Thermo Fisher Scientific), Nbea (1:1,000; rabbit polyclonal; Synaptic Systems), PSD95 (1:200; mouse monoclonal 6G6-1C9; Abcam), TGN38 (1:100; mouse monoclonal; gift from J. van Minnen, Hotchkiss Brain Institute, Calgary, Canada), transferrin receptor (1:500; mouse monoclonal H68,4; Invitrogen), VAMP2 (1:1,000; mouse monoclonal 69.1; Synaptic Systems), VGLUT1 (1:1,000; rabbit polyclonal; Synaptic Systems), VIAAT (1:1,000; rabbit polyclonal; Synaptic Systems), and vti 1 A (1:200; mouse monoclonal 45; BD). We obtained secondary antibodies from Molecular Probes (1:1,000 or 1:2,000). For fixable FM1-43 labeling, hippocampal neurons were grown for $14 \mathrm{~d}$ and then stained at $30^{\circ} \mathrm{C}$ for $10 \mathrm{~s}$ with $20 \mu \mathrm{M}$ fixable FM 1-43 (Molecular Probes) in modified depolarizing external medium containing $86 \mathrm{mM} \mathrm{K}^{+}$and $83.5 \mathrm{mM} \mathrm{Na}^{+}$immediately followed by an incubation for $30 \mathrm{~s}$ with the same dye concentration in standard external medium (167 $\mathrm{mM} \mathrm{Na}^{+}, 2.4 \mathrm{mM} \mathrm{K}, 10 \mathrm{mM}$ Hepes, $10 \mathrm{mM}$ glucose, $4 \mathrm{mM} \mathrm{Ca}^{2+}$, and $4 \mathrm{mM} \mathrm{Mg}^{2+}$ [330 mOsm/liter], pH 7.3). All further procedures were performed at RT. The cells were washed several times with external medium, fixed for 5 min with $2.5 \%$ formaldehyde in external medium, and then incubated for $15 \mathrm{~min}$ with $5 \%$ formaldehyde in PBS. Reactive sites were blocked with $25 \mathrm{mM}$ glycine in PBS for at least $30 \mathrm{~min}$. Then, cell membranes were permeabilized under mild conditions to avoid the formation of dispersive aggregates from membrane contents and the membrane staining dye. For this purpose, the cells were kept for $20 \mathrm{~min}$ in $1 \mathrm{mM}$ sodium cholate (Sigma-Aldrich) in an otherwise salt-free $300 \mathrm{mM}$ sucrose solution. Before and after the permeabilization, cells were carefully washed with $300 \mathrm{mM}$ sucrose to remove salt and detergent residues. To identify all synapses independently of their exocytotic activity, the cultures were stained for VGLUT1 and MAP2 (Jockusch et al., 2007). For WT and KO analysis, a given set was treated in parallel, and the images were taken with the same settings. For Nbea localization experiments and investigation of the developmental expression pattern of Nbea, neurons were examined on a confocal microscope (LSM 510; Carl Zeiss) with a 63x Plan Neofluar lens (NA 1.4; Carl Zeiss). Images were analyzed and further processed using ImageJ software (National Institutes of Health). For morphological analysis of WT and KO cells, neurons were stained for gephyrin, VIAAT, and MAP2, or alternatively, for PSD95, VGLUT1, and MAP2, and were observed at high magnification (UPlan Apochromat 40x; NA 1.0) with an upright epifluorescence microscope (BX61; Olympus). Images were acquired with a digital camera (F-View II; Olympus) and analyzed using AnalySIS software (Soft Imaging Systems). Synapses were counted as described previously (Varoqueaux et al., 2002). In brief, the pre-and postsynaptic markers were analyzed by first thresholding the signal to omit pixels originating from the extracellular field and by applying the separation filter to separate larger puncta. The number and intensity of puncta were measured for each cell. The dendritic arborisation was assessed using Sholl analysis, in which dendrites crossing concentric circles drawn at 7.5-um intervals around neurons are counted (Sholl, 1953), using Meta Imaging Series 6.1 software (Universal Imaging). For receptor colocalization experiments, confocal images were acquired with a confocal microscope (TCS SP2 equipped with an AOBS [acousto-optical beam splitter]; Leica) with a $63 \times$ objective lens (Plan Apochromat; NA 1.4) and analyzed using AnalySIS software.

\section{High potassium stimulation}

DIV14 WT high-density hippocampal neuron cultures were incubated for 2 min with either fresh prewarmed culture medium or culture medium containing $60 \mathrm{mM} \mathrm{KCl}$ and afterward immediately fixed in 3.7\% formaldehyde. After fixation, cells were costained for MAP2, endogenous Nbea, and GM130 or VAMP2.

\section{Receptor labeling assays}

Live hippocampal neurons at DIV16 were labeled for 10 min at $37^{\circ} \mathrm{C}$ with an antibody directed against the extracellular $\mathrm{N}$-terminal domain of the AMPA receptor subunit GluA2 (1:200; EMD Millipore) or the GABA $A_{A}$ receptor subunit $\mathrm{GABA}_{A}-\gamma 2$ (1:2,000; J.M. Fritschy, Eidgenössische Technische Hochschule, Zurich, Switzerland; Fritschy and Mohler, 1995). The synaptic localization of GluA2 and $\mathrm{GABA}_{\mathrm{A}-} \gamma 2$ was quantified by their apposition to VGLUT1 and VIAAT, respectively. The cells were then mounted and observed at high magnification $(63 x)$ with an upright epifluorescence microscope (BX61). For the receptor internalization assay, live neurons were labeled with an anti-GluA2 antibody for $10 \mathrm{~min}$ at $37^{\circ} \mathrm{C}$ and then washed and placed back into the medium of the cells at $37^{\circ} \mathrm{C}$ for 0,10 , 
30 , or $60 \mathrm{~min}$. The neurons were then fixed in $4 \%$ PFA and stained with Alexa Fluor 488-labeled anti-mouse antibodies under nonpermeabilizing conditions. Subsequently, the neurons were permeabilized and stained with Alexa Fluor 555-labeled anti-mouse antibodies to stain endocytosed receptors. Confocal images were acquired with a confocal microscope (TCS SP2 equipped with AOBS) with a $63 \times$ objective lens (Plan Apochromat; NA 1.4). Red fluorescence intensities indicative of internalization were divided by total (red + green) fluorescence intensities to control for cell density. Units of internalization were measured as red/total fluorescence (Lin et al., 2000; Varoqueaux et al., 2006). For experiments performed to assess activity-dependent changes, cells were stimulated with $60 \mathrm{mM} \mathrm{KCl}$ for $2 \mathrm{~min}$. After this, cells were fixed and stained for GluA2containing receptors or the endocytosis experiment was performed as described previously in this paragraph.

\section{Protein analysis}

Protein levels in mouse E1 8 brain homogenate and lysates prepared from cultured neurons were assessed by immunoblotting using primary antibodies to the following antigens: actin (1:4,000; mouse monoclonal; SigmaAldrich), $\mathrm{GABA}_{A^{-}-\alpha} 1$ (1:1,000; rabbit polyclonal; EMD Millipore), GABA $A_{A-\alpha} 5$ (1:2,000; rabbit antibody; Brünig et al., 2002), GABA $A_{A}-\gamma 2$ (1:1,000; rabbit polyclonal; Abcam), GluA1 1:1,000; rabbit polyclonal; EMD Millipore), GluA2/3 (1:1,000; rabbit polyclonal; EMD Millipore), GluK2/3 (1:1,000; rabbit polyclonal; EMD Millipore), GluN1 (1:1,000; mouse monoclonal M68; Synaptic Systems), GluN2A (1:1,000; rabbit polyclonal; EMD Millipore), Munc 13-1 (1:1,000; Rhee et al., 2002), Nbea (1:500; rabbit polyclonal; Synaptic Systems), NL1 (1:5,000; mouse monoclonal 4C 12; Synaptic Systems), PSD95 (1:2,000; mouse monoclonal 6G6-1C9; Abcam), synapsin 1 (1:2,000; rabbit polyclonal; Synaptic Systems), synaptophysin (1:400,000; mouse monoclonal; Synaptic Systems), synaptotag$\min 1$ (1:2,500; mouse monoclonal; Synaptic Systems), transferrin receptor (1:2,000; mouse monoclonal H68,4), tubulin (1:30,000; mouse monoclonal; Sigma-Aldrich), vasoline-containing peptide (1:500; rabbit polyclonal; gift of T. Südhof, Stanford University School of Medicine, Palo Alto, CA), VGLUT1 (1:2,000; rabbit polyclonal; Synaptic Systems), and VIAAT (1:1,000; rabbit polyclonal against the luminal domain; Synaptic Systems). Western blots were processed with peroxidase-labeled secondary antibodies (1:5,000; Sigma-Aldrich) and developed with ECL. Western blot signals on film were quantified using ImageJ.

\section{Biotinylation assay}

Live hippocampal neurons in high-density culture were washed with the extracellular solution and incubated with $0.5 \mathrm{mg} / \mathrm{ml}$ biotin (Thermo Fisher Scientific) for $30 \mathrm{~min}$ at RT. The unbound biotin was removed with a glycine wash, and the cells were lysed using radioimmunoprecipitation assay buffer $150 \mathrm{mM}$ Tris $/ \mathrm{HCl}, \mathrm{pH} 7.4,150 \mathrm{mM} \mathrm{NaCl}, 10 \mathrm{mM}$ EDTA, $1 \%$ Triton $\mathrm{X}-100,0.1 \%$ SDS, and protease inhibitors $17.4 \mathrm{\mu g} / \mathrm{ml} \mathrm{PMSF}, 1 \mathrm{\mu g} / \mathrm{ml}$ aprotinin, and $0.5 \mathrm{\mu g} / \mathrm{ml}$ leupeptin). The cells were scraped off and centrifuged at $14,000 \mathrm{~g}$ for $15 \mathrm{~min}$ at $4{ }^{\circ} \mathrm{C}$. The supernatant was collected, and the protein concentrations were measured using bicinchoninic acid (Thermo Fisher Scientific). Equal amounts of control and Nbea KO proteins were incubated with streptavidin beads to capture biotinylated proteins. After washing in extraction buffer, biotinylated proteins were eluted from streptavidin beads by boiling in SDS-PAGE sample buffer, separated by SDS-PAGE, and immunoblotted.

\section{Deglycosylation assay}

Neuron culture lysates were collected and treated with glycoprotein denaturing buffer (New England Biolabs, Inc.). The lysates were boiled for 10 min and incubated with endoglycosidase H and PNGase F (New England Biolabs, Inc.) according to the manufacturer's instructions. Samples were analyzed using 7.5\% SDS-PAGE gels and immunoblotted. Quantification of ratios between the levels of mature and immature proteins was assessed based on endoglycosidase $\mathrm{H}$ sensitivity. For each brain sample and protein, data were obtained by dividing the intensity of the band representing the endoglycosidase $\mathrm{H}$-insensitive protein fraction (i.e., higher molecular weight bands at the level of the bands detected in the respective untreated control samples) by the intensity of the band reflecting the endoglycosidase $\mathrm{H}-$ sensitive protein fraction (i.e., lower molecular weight bands at the level of the band detected in the respective PNGase samples).

\section{Data analysis}

All data in this study are provided as means \pm SEM and were always obtained in at least two independent experiments. For colocalization analysis of immunostained proteins, only confocal images of somata and dendrites with a resolution of 1,024 × 1,024 pixels were used. Each image was analyzed using ImageJ (version 1.44I). The background was subtracted using the Subtract Background function, and then, the Intensity Correlation Analysis plugin was used to obtain the Pearson's Correlation coefficient and Manders' overlap coefficient (Manders et al., 1993). Protein concentrations were measured with the bicinchoninic acid assay. Protein levels detected were analyzed using Image for all experiments. The developmental expression pattern of Nbea (Fig. S2 G) was assessed by making maximum projections, setting z-plane limits for acquisition $10.29-0.37 \mu \mathrm{m}$ per slice, 15-20 slices) on the basis of the fluorescence signal for Nbea. For the analyses of Nbea levels in rescued neurons (Fig. S3, D-H), of the number and size of lysosomes (Fig. S3, I-K), and of the subcellular localization of Nbea upon high potassium stimulation (Fig. S4, C-I), single-plane images of neurons $(1,024 \times 1,024$ pixels) were analyzed using SynD software (INCF Software Center; Schmitz et al., 2011 ).

\section{Statistics}

Confidence was assessed by two-tailed unpaired Student's $t$ tests between control and KO datasets using InStat software (GraphPad Software) for all statistical analyses. $n$ and $p$-values are given in the corresponding figure legends. All data are presented as means \pm SEM. In case of analyses of Nbea levels in rescued neurons (Fig. S3, D-H), of the number and size of lysosomes (Fig. S3, I-K), of the subcellular localization of Nbea upon high potassium stimulation (Fig. S4, C-II), and of exogenous glutamate application on high-density cultures of WT and KO neurons, we used MATLAB R2007a (The MathWorks, Inc.) to test our datasets for normality with Lilliefors goodness of fit and heterogeneity of variance with Bartlett's test for equality of variance. If the data allowed it, a two-tailed unpaired Student's $t$ test was performed. Alternatively, the Wilcoxon-Mann-Whitney test was used.

\section{Online supplemental material}

Fig. S1 shows unaltered neurotransmitter release properties and postsynaptic receptor function in heterozygous Nbea KO neurons. Fig. S2 shows reduced neurotransmitter responses in Nbea $\mathrm{KO}$ neurons in high-density culture but normal neurotransmitter responses in young cultures before synapse formation. Fig. S3 shows the expression levels and subcellular localization of endogenous and overexpressed Nbea in neurons and distribution of lysosomes in Nbea KO neurons. Fig. S4 shows the distribution of Nbea and several subcellular marker proteins in neurons. Fig. S5 shows the altered dendrite architecture and distribution of neurotransmitter receptors in Nbea KO neurons. Table S1 shows data on synaptic transmission parameters. Table S2 shows data from paired recordings. Table S3 shows data from rescue experiments. Table S4 shows data from morphological analyses. Online supplemental material is available at http://www.jcb .org/cgi/content/full/jcb.201207113/DC1

We thank F. Benseler, I. Beulshausen, R. Decker, J. Wortel, A. Galinski, K. Hellmann, Y. Thanhäuser, D. Schwerdffeger, and our Transgenic Animal Facitities for invaluable support. We thank M. Hoon for discussions and advice, R. Zalm for cloning the full-length Nbea cDNA construct, and T.C. Südhof, J. van Minnen, and J.M. Fritschy for kind gifts of reagents.

This work was supported by the Max Planck Society (N. Brose), a Neuromics Marie Curie Early Stage Training Grant (MEST-CT_2005-020919 to J. Lauks and M. Verhage), the Deutsche Forschungsgemeinschaft (Ki 324/15 to M.W. Kilimann and N. Brose), the Vetenskapsradet (to M.W. Kilimann), Uppsala University (Start-Up Grant to M.W. Kilimann), the EUROSPIN and Synaptic Systems Consortia (FP7-HEALTH-F2-2009-241 498 and FP7-HEALTHF2-2009-242167 to N. Brose and M. Verhage), and the Dutch Organization for Scientific Research (Veni grant 91 6-36-043 to H. de Wit).

Submitted: 17 July 2012

Accepted: 26 October 2012

\section{References}

Albers, C.A., A. Cvejic, R. Favier, E.E. Bouwmans, M.C. Alessi, P. Bertone, G. Jordan, R.N. Kettleborough, G. Kiddle, M. Kostadima, et al. 2011. Exome sequencing identifies NBEAL2 as the causative gene for gray platelet syndrome. Nat. Genet. 43:735-737. http://dx.doi.org/10 $.1038 /$ ng. 885

Bogdanov, Y., G. Michels, C. Armstrong-Gold, P.G. Haydon, J. Lindstrom, M. Pangalos, and S.J. Moss. 2006. Synaptic GABA A receptors are directly recruited from their extrasynaptic counterparts. EMBO J. 25:4381-4389. http://dx.doi.org/10.1038/sj.emboj.7601309

Bredt, D.S., and R.A. Nicoll. 2003. AMPA receptor trafficking at excitatory synapses. Neuron. 40:361-379. http://dx.doi.org/10.1016/S0896-6273(03) 00640-8 
Brünig, I., E. Scotti, C. Sidler, and J.M. Fritschy. 2002. Intact sorting, targeting, and clustering of gamma-aminobutyric acid A receptor subtypes in hippocampal neurons in vitro. J. Comp. Neurol. 443:43-55. http://dx.doi.org/ $10.1002 /$ cne. 10102

Burgalossi, A., S. Jung, K.N. Man, R. Nair, W.J. Jockusch, S.M. Wojcik, N Brose, and J.S. Rhee. 2012. Analysis of neurotransmitter release mechanisms by photolysis of caged $\mathrm{Ca}^{2+}$ in an autaptic neuron culture system. Nat. Protoc. 7:1351-1365. http://dx.doi.org/10.1038/nprot.2012.074

Burkhardt, J.K., F.A. Wiebel, S. Hester, and Y. Argon. 1993. The giant organelles in beige and Chediak-Higashi fibroblasts are derived from late endosomes and mature lysosomes. J. Exp. Med. 178:1845-1856. http://dx.doi .org/10.1084/jem.178.6.1845

Castermans, D., V. Wilquet, E. Parthoens, C. Huysmans, J. Steyaert, L. Swinnen, J.P. Fryns, W. Van de Ven, and K. Devriendt. 2003. The neurobeachin gene is disrupted by a translocation in a patient with idiopathic autism. J. Med. Genet. 40:352-356. http://dx.doi.org/10.1136/jmg.40.5.352

del Pino, I., I. Paarmann, M. Karas, M.W. Kilimann, and H. Betz. 2011. The trafficking proteins Vacuolar Protein Sorting 35 and Neurobeachin interact with the glycine receptor $\beta$-subunit. Biochem. Biophys. Res. Commun. 412:435-440. http://dx.doi.org/10.1016/j.bbrc.2011.07.110

Fritschy, J.M., and H. Mohler. 1995. GABAA-receptor heterogeneity in the adult rat brain: differential regional and cellular distribution of seven major subunits. J. Comp. Neurol. 359:154-194. http://dx.doi.org/10.1002/ cne.903590111

Fritschy, J.M., R.J. Harvey, and G. Schwarz. 2008. Gephyrin: where do we stand, where do we go? Trends Neurosci. 31:257-264. http://dx.doi.org/10 .1016/j.tins.2008.02.006

Gebauer, D., J. Li, G. Jogl, Y. Shen, D.G. Myszka, and L. Tong. 2004. Crystal structure of the PH-BEACH domains of human LRBA/BGL. Biochemistry. 43:14873-14880. http://dx.doi.org/10.1021/bi049498y

Greger, I.H., and J.A. Esteban. 2007. AMPA receptor biogenesis and trafficking. Curr. Opin. Neurobiol. 17:289-297. http://dx.doi.org/10.1016/j.conb .2007.04.007

Gunay-Aygun, M., T.C. Falik-Zaccai, T. Vilboux, Y. Zivony-Elboum, F. Gumruk, M. Cetin, M. Khayat, C.F. Boerkoel, N. Kfir, Y. Huang, et al. 2011. NBEAL2 is mutated in gray platelet syndrome and is required for biogenesis of platelet $\alpha$-granules. Nat. Genet. 43:732-734. http://dx.doi .org/10.1038/ng. 883

Hayashi, Y., S.H. Shi, J.A. Esteban, A. Piccini, J.C. Poncer, and R. Malinow. 2000. Driving AMPA receptors into synapses by LTP and CaMKII: requirement for GluR1 and PDZ domain interaction. Science. 287:22622267. http://dx.doi.org/10.1126/science.287.5461.2262

Hirokawa, N., and R. Takemura. 2004. Molecular motors in neuronal development, intracellular transport and diseases. Curr. Opin. Neurobiol. 14:564-573. http://dx.doi.org/10.1016/j.conb.2004.08.011

Introne, W., R.E. Boissy, and W.A. Gahl. 1999. Clinical, molecular, and cell biological aspects of Chediak-Higashi syndrome. Mol. Genet. Metab. 68:283-303. http://dx.doi.org/10.1006/mgme.1999.2927

Jacob, T.C., S.J. Moss, and R. Jurd. 2008. $\left.\operatorname{GABA}_{\mathrm{A}}\right)$ receptor trafficking and its role in the dynamic modulation of neuronal inhibition. Nat. Rev. Neurosci. 9:331-343. http://dx.doi.org/10.1038/nrn2370

Jockusch, W.J., D. Speidel, A. Sigler, J.B. Sørensen, F. Varoqueaux, J.S. Rhee, and N. Brose. 2007. CAPS-1 and CAPS-2 are essential synaptic vesicle priming proteins. Cell. 131:796-808. http://dx.doi.org/10.1016/j.cell.2007.11.002

Jones, M.V., and G.L. Westbrook. 1996. The impact of receptor desensitization on fast synaptic transmission. Trends Neurosci. 19:96-101. http://dx.doi .org/10.1016/S0166-2236(96)80037-3

Kahr, W.H., J. Hinckley, L. Li, H. Schwertz, H. Christensen, J.W. Rowley, F.G. Pluthero, D. Urban, S. Fabbro, B. Nixon, et al. 2011. Mutations in NBEAL2, encoding a BEACH protein, cause gray platelet syndrome. Nat. Genet. 43:738-740. http://dx.doi.org/10.1038/ng.884

Köhrmann, M., W. Haubensak, I. Hemraj, C. Kaether, V.J. Lessmann, and M.A. Kiebler. 1999. Fast, convenient, and effective method to transiently transfect primary hippocampal neurons. J. Neurosci. Res. 58:831-835. http://dx.doi.org/10.1002/(SICI)1097-4547(19991215)58:6<831:: AID-JNR10>3.0.CO;2-M

Lauks, J., P. Klemmer, F. Farzana, R. Karupothula, R. Zalm, N.E. Cooke, K.W. Li, A.B. Smit, R. Toonen, and M. Verhage. 2012. Synapse associated protein 102 (SAP102) binds the C-terminal part of the scaffolding protein neurobeachin. PLOS ONE. 7:e39420. http://dx.doi.org/10.1371/journal .pone. 0039420

Lin, J.W., W. Ju, K. Foster, S.H. Lee, G. Ahmadian, M. Wyszynski, Y.T. Wang, and M. Sheng. 2000. Distinct molecular mechanisms and divergent endocytotic pathways of AMPA receptor internalization. Nat. Neurosci. 3:1282-1290. http://dx.doi.org/10.1038/81814

Lopez-Herrera, G., G. Tampella, Q. Pan-Hammarström, P. Herholz, C.M. Trujillo-Vargas, K. Phadwal, A.K. Simon, M. Moutschen, A. Etzioni, A. Mory, et al. 2012. Deleterious mutations in LRBA are associated with a syndrome of immune deficiency and autoimmunity. Am. J. Hum. Genet. 90:986-1001. http://dx.doi.org/10.1016/j.ajhg.2012.04.015

Malinow, R., and R.C. Malenka. 2002. AMPA receptor trafficking and synaptic plasticity. Annu. Rev. Neurosci. 25:103-126. http://dx.doi.org/10.1146/ annurev.neuro.25.112701.142758

Manders, E.M.M., F.J. Verbeek, and J.A. Aten. 1993. Measurement of colocalization of objects in dual-colour confocal images. J. Microsc. 169: 375-382. http://dx.doi.org/10.1111/j.1365-2818.1993.tb03313.x

Medrihan, L., A. Rohlmann, R. Fairless, J. Andrae, M. Döring, M. Missler, W. Zhang, and M.W. Kilimann. 2009. Neurobeachin, a protein implicated in membrane protein traffic and autism, is required for the formation and functioning of central synapses. J. Physiol. 587:5095-5106. http://dx.doi .org/10.1113/jphysiol.2009.178236

Nagle, D.L., M.A. Karim, E.A. Woolf, L. Holmgren, P. Bork, D.J. Misumi, S.H. McGrail, B.J. Dussault Jr., C.M. Perou, R.E. Boissy, et al. 1996. Identification and mutation analysis of the complete gene for ChediakHigashi syndrome. Nat. Genet. 14:307-311. http://dx.doi.org/10.1038/ ng1196-307

Newpher, T.M., and M.D. Ehlers. 2008. Glutamate receptor dynamics in dendritic microdomains. Neuron. 58:472-497. http://dx.doi.org/10.1016/ j.neuron.2008.04.030

Niesmann, K., D. Breuer, J. Brockhaus, G. Born, I. Wolff, C. Reissner, M.W. Kilimann, A. Rohlmann, and M. Missler. 2011. Dendritic spine formation and synaptic function require neurobeachin. Nat. Commun. 2:557. http://dx.doi.org/10.1038/ncomms 1565

Olszewski, P.K., J. Rozman, J.A. Jacobsson, B. Rathkolb, S. Strömberg, W. Hans, A. Klockars, J. Alsiö, U. Risérus, L. Becker, et al. 2012. Neurobeachin, a regulator of synaptic protein targeting, is associated with body fat mass and feeding behavior in mice and body-mass index in humans. PLoS Genet. 8:e1002568. http://dx.doi.org/10.1371/journal.pgen.1002568

O’Neal, J., F. Gao, A. Hassan, R. Monahan, S. Barrios, M.W. Kilimann, I. Lee, W.J. Chng, R. Vij, and M.H. Tomasson. 2009. Neurobeachin (NBEA) is a target of recurrent interstitial deletions at 13q13 in patients with MGUS and multiple myeloma. Exp. Hematol. 37:234-244. http://dx.doi.org/ 10.1016/j.exphem.2008.10.014

Pettit, D.L., S. Perlman, and R. Malinow. 1994. Potentiated transmission and prevention of further LTP by increased CaMKII activity in postsynaptic hippocampal slice neurons. Science. 266:1881-1885. http://dx.doi.org/10 $1126 /$ science. 7997883

Prybylowski, K., and R.J. Wenthold. 2004. N-Methyl-D-aspartate receptors: subunit assembly and trafficking to the synapse. J. Biol. Chem. 279:96739676. http://dx.doi.org/10.1074/jbc.R300029200

Rhee, J.S., A. Betz, S. Pyott, K. Reim, F. Varoqueaux, I. Augustin, D. Hesse, T.C. Südhof, M. Takahashi, C. Rosenmund, and N. Brose. 2002. Beta phorbol ester- and diacylglycerol-induced augmentation of transmitter release is mediated by Munc13s and not by PKCs. Cell. 108:121-133. http://dx.doi.org/10.1016/S0092-8674(01)00635-3

Rosenmund, C., and C.F. Stevens. 1996. Definition of the readily releasable pool of vesicles at hippocampal synapses. Neuron. 16:1197-1207. http:// dx.doi.org/10.1016/S0896-6273(00)80146-4

Schlüter, O.M., W. Xu, and R.C. Malenka. 2006. Alternative N-terminal domains of PSD-95 and SAP97 govern activity-dependent regulation of synaptic AMPA receptor function. Neuron. 51:99-111. http://dx.doi.org/10 .1016/j.neuron.2006.05.016

Schmitz, S.K., J.J. Hjorth, R.M. Joemai, R. Wijntjes, S. Eijgenraam, P. de Bruijn, C. Georgiou, A.P. de Jong, A. van Ooyen, M. Verhage, et al. 2011. Automated analysis of neuronal morphology, synapse number and synaptic recruitment. J. Neurosci. Methods. 195:185-193. http://dx.doi org/10.1016/j.jneumeth.2010.12.011

Schwenk, J., N. Harmel, G. Zolles, W. Bildl, A. Kulik, B. Heimrich, O. Chisaka, P. Jonas, U. Schulte, B. Fakler, and N. Klöcker. 2009. Functional proteomics identify cornichon proteins as auxiliary subunits of AMPA receptors. Science. 323:1313-1319. http://dx.doi.org/10.1126/science.1167852

Shi, S., Y. Hayashi, J.A. Esteban, and R. Malinow. 2001. Subunit-specific rules governing AMPA receptor trafficking to synapses in hippocampal pyramidal neurons. Cell. 105:331-343. http://dx.doi.org/10.1016/ S0092-8674(01)00321-X

Sholl, D.A. 1953. Dendritic organization in the neurons of the visual and motor cortices of the cat. J. Anat. 87:387-406.

Su, Y., R.J. Balice-Gordon, D.M. Hess, D.S. Landsman, J. Minarcik, J. Golden, I. Hurwitz, S.A. Liebhaber, and N.E. Cooke. 2004. Neurobeachin is essential for neuromuscular synaptic transmission. J. Neurosci. 24:36273636. http://dx.doi.org/10.1523/JNEUROSCI.4644-03.2004

Tomita, S., V. Stein, T.J. Stocker, R.A. Nicoll, and D.S. Bredt. 2005. Bidirectional synaptic plasticity regulated by phosphorylation of stargazin-like TARPs. Neuron. 45:269-277. http://dx.doi.org/10.1016/j.neuron.2005.01.009

Varoqueaux, F., A. Sigler, J.S. Rhee, N. Brose, C. Enk, K. Reim, and C. Rosenmund. 2002. Total arrest of spontaneous and evoked synaptic 
transmission but normal synaptogenesis in the absence of Munc13-mediated vesicle priming. Proc. Natl. Acad. Sci. USA. 99:9037-9042. http:// dx.doi.org/10.1073/pnas.122623799

Varoqueaux, F., G. Aramuni, R.L. Rawson, R. Mohrmann, M. Missler, K. Gottmann, W. Zhang, T.C. Südhof, and N. Brose. 2006. Neuroligins determine synapse maturation and function. Neuron. 51:741-754. http:// dx.doi.org/10.1016/j.neuron.2006.09.003

von Engelhardt, J., V. Mack, R. Sprengel, N. Kavenstock, K.W. Li, Y. SternBach, A.B. Smit, P.H. Seeburg, and H. Monyer. 2010. CKAMP44: a brain-specific protein attenuating short-term synaptic plasticity in the dentate gyrus. Science. 327:1518-1522. http://dx.doi.org/10.1126/science .1184178

Wang, N., W.I. Wu, and A. De Lozanne. 2002. BEACH family of proteins: phylogenetic and functional analysis of six Dictyostelium BEACH proteins. J. Cell. Biochem. 86:561-570. http://dx.doi.org/10.1002/jcb.10254

Wang, X., F.W. Herberg, M.M. Laue, C. Wullner, B. Hu, E. Petrasch-Parwez, and M.W. Kilimann. 2000. Neurobeachin: A protein kinase A-anchoring, beige/Chediak-higashi protein homolog implicated in neuronal membrane traffic. J. Neurosci. 20:8551-8565.

Wenthold, R.J., R.S. Petralia, I.I. Blahos J, and A.S. Niedzielski. 1996. Evidence for multiple AMPA receptor complexes in hippocampal CA1/CA2 neurons. J. Neurosci. 16:1982-1989.

Wojcik, S.M., J.S. Rhee, E. Herzog, A. Sigler, R. Jahn, S. Takamori, N. Brose, and C. Rosenmund. 2004. An essential role for vesicular glutamate transporter 1 (VGLUT1) in postnatal development and control of quantal size. Proc. Natl. Acad. Sci. USA. 101:7158-7163. http://dx.doi .org/10.1073/pnas.0401764101

Wojcik, S.M., S. Katsurabayashi, I. Guillemin, E. Friauf, C. Rosenmund, N. Brose, and J.S. Rhee. 2006. A shared vesicular carrier allows synaptic corelease of GABA and glycine. Neuron. 50:575-587. http://dx.doi.org/ 10.1016/j.neuron.2006.04.016

Zhao, H., Y.L. Boissy, Z. Abdel-Malek, R.A. King, J.J. Nordlund, and R.E. Boissy. 1994. On the analysis of the pathophysiology of Chediak-Higashi syndrome. Defects expressed by cultured melanocytes. Lab. Invest. 71: 25-34. 